\title{
Linking plant growth promoting arbuscular mycorrhizal colonization with bacterial plant sulfur supply
}

Authors: Jacinta Gahan, and Achim Schmalenberger

5

Department of Biological Sciences, School of Natural Sciences, University of Limerick,

Limerick, Ireland

10 Corresponding author*: Achim Schmalenberger,

Department of Biological Sciences,

University of Limerick,

Park Road, Castletroy,

Limerick, V94T9PX,

15

Rep. of Ireland 


\section{Abstract}

Sulfur (S) exists in organically bound complexes ( 95\%), predominantly as sulfonates, and are not directly plant available. Specific soil bacteria can mobilise sulfonates but very

20 little is known about these bacteria in the hyphosphere. Since mycorrhizal fungi support growth of the majority of land plants, hyphosphere desulfonating bacteria may be of substantial benefit to the plant host. This study analysed the effect of AM inoculation with Rhizophagus irregularis (former G. intraradices, Glomus) and a mix of six AM species (Mixed) on PGP, microbial communities and sulfonate mobilising bacteria with $L$.

25 perenne, Agrostis stolonifera and Plantago lanceolata as plant hosts in bi-compartmental microcosms and A. stolonifera in PGP pot experiments. AM inoculation significantly increased plant growth, percentage root colonisation and the quantity of cultivable desulfonating bacteria in the hyphosphere over pre-inoculated soil for all plants. Community analysis via PCR-DGGE revealed significantly different bacterial and fungal

30 communities post inoculation. Analysis of the sulfonate mobilising asfA gene revealed a significantly altered community and novel bacterial isolates with this important functional ability post-inoculation. The results demonstrate that AM inoculation increased plant biomass yield, AM root colonisation and altered bacterial and fungal community dynamics in the hyphosphere. AM inoculated microcosms had an increased abundance 35 of desulfonating bacteria that may be beneficial for plant-S supply. 


\section{Research highlights}

- Inoculation with AM fungi was shown to promote plant growth and harbour larger

40 populations of sulfonate mobilising bacteria.

- Post-inoculation hyphospheric bacterial and saprotrophic fungal communities were shown to differ significantly in composition and abundance.

45 - Analysis of sulfonate mobilising bacteria revealed novel presumptive species in possession of the asfA gene associated with AM hyphae.

- AM inoculation was shown to significantly impact the asfA positive bacterial community composition. 


\section{Introduction}

Agricultural land has been subjected to human induced degradation in recent years as a result of intensification of agricultural practices leading to ecosystem alterations including soil degradation and erosion (Barrios, 2007). Restoration and sustainable management of agricultural land is a necessity given the growing global population,

55 estimated to double by 2050 , and increased demand from agricultural land projected to be $60-110 \%$ of the current rate (Ray et al., 2013).

Arbuscular Mycorrhizal (AM) fungi are ubiquitous soil microorganisms that form endosymbiotic partnerships with most land plants. They exist in almost all terrestrial ecosystems where they may be involved in sustainable ecosystem services, for example,

60 in nutrient depleted agricultural soils (Öpik et al., 2006). AM fungi are close to being eradicated from agricultural land under current practices which include; tillage (Johansson et al., 2004), crop rotation (Plenchette et al., 2005) and application of agrochemicals (Bünemann et al., 2006).

In recent years, the use of commercially available AM inocula to restore native AM fungal

65 communities has been investigated with the objective of maximising the many biotic and abiotic benefits of an intact symbiosis. These benefits include i) improved nutrient acquisition, ii) stabilisation of soil aggregates, iii) prevention of erosion and iv) alleviation of potential plant stress factors (Wang et al., 2011, Andrade et al., 2013). These investigations have often presented conflicting results (Gianinazzi \& Vosátka, 2004,

70 Rowe et al., 2007, Faye et al., 2013). What these studies highlight is that optimisation of AM inoculation strategies requires specialist management practices. These practices include i) careful inoculum selection to ensure quality and suitability to the host plant, ii) minimal tillage, iii) intelligent crop rotation (non-mycorrhizal should not precede mycorrhizal crops), iv) organic fertilisation practices, and v) avoiding use of 
75 agrochemicals i.e. pesticides (Dodd \& Ruiz-Lozano, 2012, Berruti et al., 2014) wherever possible.

Stricter governance of air pollution has led to greatly reduced inorganic S deposition to soils. A simultaneous increase in high yielding crop varieties has further depleted soil of plant available $\mathrm{SO}_{4}{ }^{2-}$ stocks (McGrath et al., 2003). Soil S exists up to $95 \%$ organically

80 bound (Autry \& Fitzgerald, 1990), predominantly as aliphatic and aromatic sulfonates (30-70\%) and sulfate esters (20-60\%), and is not directly available to plants (Zhao et al., 2006). Hydrolysis of the sulfate ester bond is facilitated by bacteria and saprotrophic fungi, however, aromatic sulfonate mobilisation is facilitated solely by specific bacteria (Schmalenberger \& Kertesz, 2007). Many bacteria isolated from soil possess the ability

85 to mobilise aliphatic sulfonates (King \& Quinn, 1997), however, aromatic sulfonate mobilisation has been shown to be more deterministic of plant S nutrition. Indeed, mobilisation of aromatic sulfonates has been shown to promote the growth of tomato plants (Kertesz \& Mirleau, 2004) and Arabidopsis plants (Kertesz et al., 2007). The genetic organisation of this activity is catalysed by a $\mathrm{FMNH}_{2}$-dependent monooxygenase

90 enzyme complex encoded in the ssu gene cluster (Eichhorn et al., 1999). The monooxygenase $\mathrm{SsuD}$ cleaves sulfonates to aldehydes and the reduced flavin for this process is provided by the FMN-NADPH reductase SsuE. For aromatic desulfonation an additional asfRABC gene cluster is required and the asfA gene is a marker for this activity (Vermeij et al., 1999, Schmalenberger \& Kertesz, 2007).

95 Studies on aromatic desulfonating bacterial phylogeny identified numerous BetaProteobacteria; Variovorax, Polaromonas, Hydrogenophaga, Cupriavidus, Burkholderia (now Paraburkholderia) and Acidovorax, the Actinobacteria; Rhodococcus and the Gamma-Proteobacteria; Pseudomonas (Schmalenberger \& Kertesz, 2007, Schmalenberger et al., 2008, Schmalenberger et al., 2009, Fox et al., 2014). Additionally, 
100 Stenotrophomonas and Williamsia species have been isolated from AM hyphae (Gahan \& Schmalenberger, 2015).

Plants rely on microbial populations for mobilisation of otherwise unavailable nutrients from soil. AM fungi have been shown to play an important role in mobilisation of $\mathrm{P}$ (Read \& Perez-Moreno, 2003) and N (Hodge et al., 2001), however, their role in mobilisation

105 of the essential macro-nutrient $\mathrm{S}$ remains unclear. AM fungi increase the nutritive absorptive surface area of their host plant via their extraradical hyphae (ERH) providing a niche for interacting with organo-S mobilising bacteria (Barea et al., 2002). Additionally, AM symbiosis alters the chemical composition of their host plants exudates which may stimulate functional bacterial populations (Lynch \& Whipps, 1990). Addition

110 of methyl-ester sulfonates (MES) to soil was shown to stimulate ERH growth putatively as a result of sulfonate mobilising bacterial metabolites (Vilarino et al., 1997). Enhanced ERH growth may stimulate further bacterial proliferation in a potential positive feedback loop.

The hypothesis of this study was that AM inoculation may increase colonisation rates,

115 host plant biomass yield, and alter organo-S mobilising microbial communities. Effectively manipulated, inoculation with AM fungi has potential to enhance output from agricultural land. It is imperative that the land is sustainably managed with limited inorganic fertilisation input whilst utilising the beneficial properties of AM fungi to reduce agrochemical requirement. It is necessary to understand the full potential of AM

120 inoculation practices as demand from agricultural land increases and available stocks of essential macro-nutrients for fertilisation are depleted (Smit et al., 2009). 


\section{Materials and Methods}

\subsection{Site description}

The soil used to create the subsequent experiments was obtained from Teagasc,

125 Johnstown Castle, Co. Wexford, Ireland (52 $16^{\circ} \mathrm{N}, 6^{\circ} 30^{\prime} \mathrm{W}, 30 \mathrm{~m}$ above sea level). The soil type is a poorly drained gley soil ( $\mathrm{pH}$ 6), organic matter (11\%), and loamy topsoil (18\% clay), classified as Mollic Histic Stagnosol (WRB 2006). The soil used has not received P or S fertiliser since 1968 and has not been ploughed since 1970 (P0-0, site 5A). Swards are mixtures of L. perenne, D. glomerata, and various meadow grass species 130 (Tunney et al., 2010).

\subsubsection{Bi-compartmental Microcosms}

Bi-compartmental microcosms were established using $120 \mathrm{~g}$ of a one part sand (Glenview Natural Stone, Ireland) to soil (Teagasc, Johnstown Castle) mixture. These systems were established to ascertain the bacterial and fungal community response to inoculation with

135 AM fungi. The bi-compartmental systems were composed of 2 Plexiglas plates $(12 \times 12$ $\mathrm{cm}$ ) (Access Plastics, Ireland) encasing two $0.5 \mathrm{~cm}$ layers of soil separated by a $35 \mu \mathrm{m}$ nylon mesh layer (Plastok Associates Ltd, Great Britain). Mesh of this size is sufficiently small to allow mycorrhizal cross colonisation while preventing root access. In the first compartment, Lolium perenne, Agrostis stolonifera, or, Plantago lanceolata (Emorsgate

140 Seeds, UK) were planted (Figure 1a) and a second root free compartment (Figure 1b) was either; left un-inoculated as a control (C treatment), inoculated with $1.8 \mathrm{~g}$ of Rhizophagus irregularis, purchased as Glomus intraradices (Glomus treatment), or inoculated with a commercial mix of 6 different AM fungi including; G. intraradices (now Rhizophagus irregularis), G. mosseae (now Funneliformis mosseae), G. etunicatum, G. hoi, G. 
The commercial AM mixed inoculum is supplied as dry granules containing 150 infective propagules (IP) per $\mathrm{g}$ and additives in this inoculum include; natural clay carriers, bioactives supporting AM symbiosis (chitin, keratin, natural humates, seaweed extract, and ground minerals), and powered biodegradable gel. The Glomus treatment did not contain 150 these additives and the substrate used in this instance was perlite. For all 3 plants, treatments were carried out in quadruplicate and the plant systems were grown in an A1000 Adaptis plant growth chamber (Conviron, Germany) with day-night temperature of $25-15^{\circ} \mathrm{C}$, respectively, a $12 \mathrm{~h}$ day length, $70 \%$ relative humidity $(\mathrm{RH})$, and $320 \mu$ moles $\mathrm{m}^{-2} \mathrm{~s}^{-2}$ photosynthetically active radiation (PAR). The systems were watered and misted 155 with distilled water $\left(\mathrm{dH}_{2} \mathrm{O}\right)$ three times a week, and fortnightly supplemented with modified Hoagland's solution (50\% nutrient concentration but without any S, S free) (Hoagland and Snyder 1933). After 6 months of growth, the systems were harvested and analysed for bacterial and fungal community diversity and bacterial sulfonate mobilising activity.

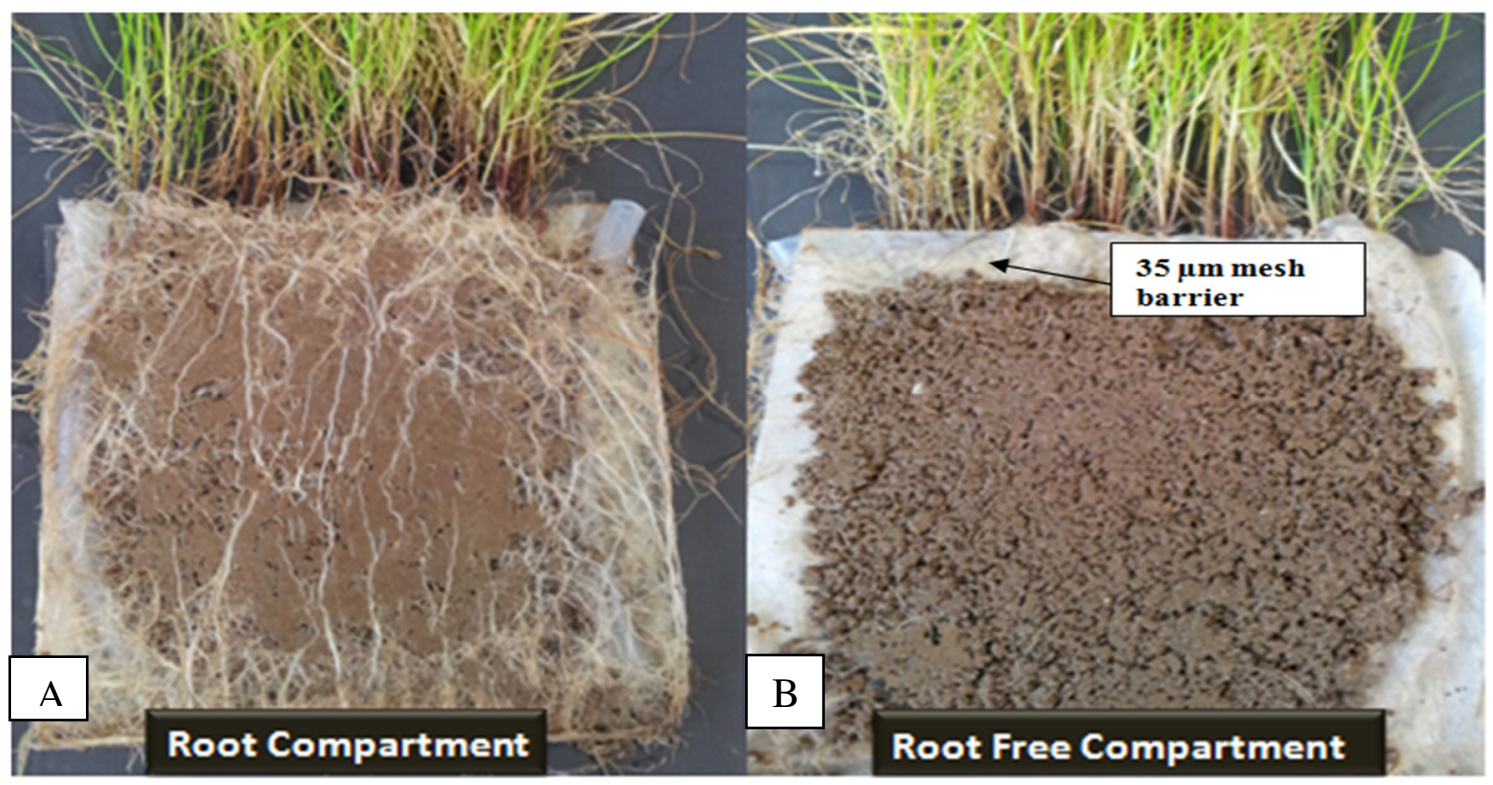

Figure 1 - Bi-compartmental microcosms (A) the plant root compartment (B) the root free arbuscular mycorrhiza compartment, and a selectively penetrable nylon mesh (35 $\mu \mathrm{m})$. 
bioRxiv preprint doi: https://doi.org/10.1101/2021.06.22.449381; this version posted June 22,2021 . The copyright holder for this preprint (which was not certified by peer review) is the author/funder, who has granted bioRxiv a license to display the preprint in perpetuity. It is made available under aCC-BY-NC-ND 4.0 International license.

\subsubsection{PGP pot experiments}

Pot experiments were established using A. stolonifera as host plant to determine the 165 impact of AM inoculation practices on PGP (Plant Growth Promotion) and on sulfonate mobilising bacterial communities. Plants of A. stolonifera were grown in $200 \mathrm{~g}$ of one part sand to soil mixture. Four experiments were established in replicates of 5 (Figure 2).

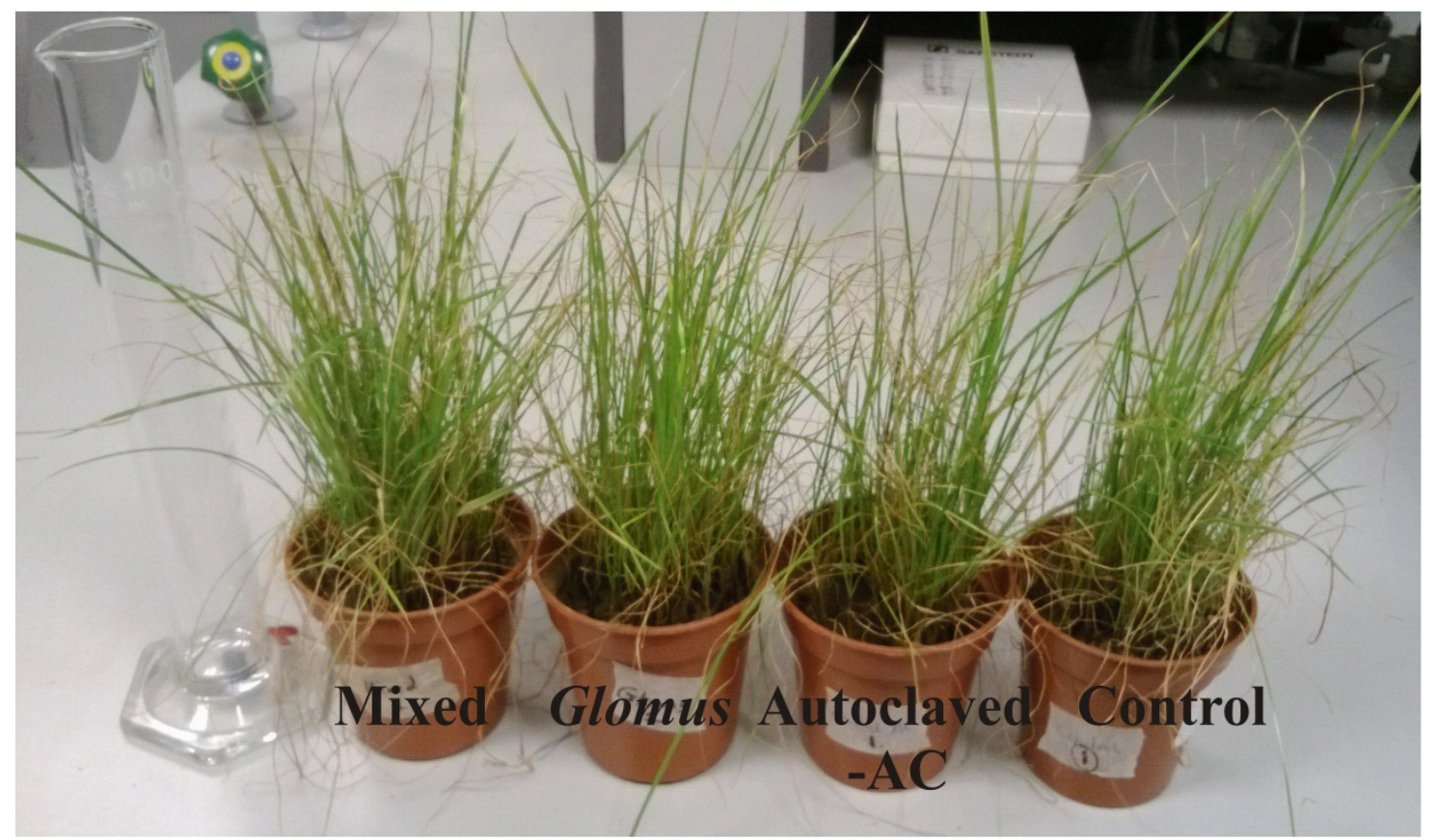
inoculant, AC = autoclaved inoculum, Glomus = Rhizophagus irregularis inoculum, Mixed = AM mix inoculum, Bulk Soil = untreated soil.

The first control did not receive AM inoculant to assess the activity of the native AM fungal community and compare that with post-inoculation treatments. The second control received an inactivated commercial mixed inoculum (see above; autoclaved for $15 \mathrm{~min}$,

$175121{ }^{\circ} \mathrm{C}$ ) to establish if there was any abiotic element in the inoculum exerting a PGP effect (Autoclaved control $=\mathrm{AC}$ ). The third treatment received a mono species Rhizophagus irregularis inoculation (Glomus), while the final treatment received the viable mixed AM fungi inoculation (Mixed). For all experiments, each pot received 100 A. stolonifera seeds and, for all experimental treatments (AC, Glomus and Mixed), $3 \mathrm{~g}$ of the respective 
180 inoculant. All treatments were grown for 10 weeks in an A1000 Adaptis plant growth chamber (Conviron, Germany) as described above.

\subsection{Percentage root colonisation}

At the time of harvest for both bi-compartmental microcosms and PGP pot experiments, each plant and treatment was examined for percentage root colonisation by AM fungi

185 using a modified version of the grid line intersect technique (McGonigle et al., 1990). A representative population of roots ( 2 root fragments, $10 \mathrm{~cm}$ in length were picked from the top, middle, and bottom of the microcosms/pots) and cut into $1 \mathrm{~cm}$ segments. The roots were stained with $10 \% \mathrm{KOH}(\mathrm{w} / \mathrm{v})$ for $12 \mathrm{~h}$. The segments were washed with $\mathrm{dH}_{2} \mathrm{O}$ and covered with alkaline $\mathrm{H}_{2} \mathrm{O}_{2}$ to bleach for $60 \mathrm{~min}$. The bleaching solution was

190 discarded and the roots were rinsed thoroughly with water. Roots were acidified in a 0.1 $\mathrm{M} \mathrm{HCl}$ solution for $12 \mathrm{~h}$ to ensure staining of intracellular fungal structures. The $\mathrm{HCl}$ solution was discarded and the roots were covered with a lactoglycerol trypan blue stain (lactic acid: glycerol: $\mathrm{H}_{2} \mathrm{O}$ in a 1:1:1 ratio, with $0.05 \%(\mathrm{w} / \mathrm{v})$ trypan blue) and incubated at $90{ }^{\circ} \mathrm{C}$ for $45 \mathrm{~min}$. The stained roots were then removed and covered in lactoglycerol

195 de-stain (minus trypan blue) overnight prior to examination. The $1 \mathrm{~cm}$ root segments were examined one field of view at a time (x 1000 magnification). The field of view was moved in reference to a graticule inserted into the eyepiece and the point of intersection was determined at the position of the graticule's vertical crosshair intersecting the root (McGonigle et al., 1990).

200 Once the point of intersection was noted, the field of view was moved across the surface area of the root and the presence of (1) arbuscules (2) vesicles and (3) hyphae was noted as 'negative' (no fungal structures), 'arbuscules', 'vesicles', or 'hyphae only'. If the crosshair intersected an arbuscule or vesicle, the respective category was increased by 
one and the total number of intersections was also increased by one. This was also the

205 case for the 'hyphae only' category. In the case of both arbuscules and vesicles being recorded at an intersection, the individual categories were both incremented but the total number of intersections was increased only by one. Arbuscular and vesicular colonisation (AC and VC, respectively) was calculated by dividing their respective counts by the total number of intersections examined i.e. if AC was observed in 50 of 100 intersections:

$21050 / 100=0.5$ or $50 \%$. Hyphal colonisation $(\mathrm{HC})$ was calculated as a proportion of the nonnegative intersections. For both bi-compartmental microcosms and pot experiments, 3 replicates of 100 intersections per treatment, per plant were examined to calculate AM fungal colonisation.

\section{2.3. Extraction and quantification of bacteria from AM hyphae}

\subsubsection{Bi-compartmental microcosms}

To harvest the bi-compartmental microcosms, in-depth morphological assessment was used to pick $0.5 \mathrm{~g}$ of hyphae from the root free compartment of the control experiment and the inoculation treatments using a compound microscope (x 100 magnification) and

220 fine forceps (Hodge \& Fitter, 2010). Detailed microscopic observations of the picked hyphae confirmed typical anatomical features of AM fungi and the absence of defined septa (Humphreys et al., 2010). As a control, $0.5 \mathrm{~g}$ of bulk soil (BS), i.e. soil not under the influence of roots or hyphae, was analysed in parallel. Loosely attached soil was removed from the picked hyphae by dipping in sterile $\mathrm{dH}_{2} \mathrm{O}$, and associated bacteria were

225 then extracted into $10 \mathrm{~mL}$ of sterile saline solution $(0.85 \% \mathrm{w} / \mathrm{v})$ by shaking at $75 \mathrm{rpm}$ on an Elmi Intelli-Mixer RM-2 (Elmi Tech Ltd, Latvia) for 30 min at $4{ }^{\circ} \mathrm{C}$. At this point, an 
aliquot was taken and used to quantify bacterial communities. Following this, the treatments were centrifuged at $4500 \mathrm{rpm}$ and $4{ }^{\circ} \mathrm{C}$ for $20 \mathrm{~min}$ and the pellet was frozen immediately $\left(-18^{\circ} \mathrm{C}\right)$ for downstream cultivation independent community analysis.

230 Using the aliquot of bacterial suspension, $100 \mu \mathrm{L}$ was added to $900 \mu \mathrm{L}$ of saline solution $(0.85 \% \mathrm{w} / \mathrm{v})$ and a series of 7 tenfold serial dilutions were performed. Most Probable Number (MPN) analysis was undertaken in liquid R2A (Reasoner \& Geldreich, 1985) and MM2TS (Fox et al., 2014) to enumerate the cultivable heterotrophic and sulfonate mobilising communities. A $20 \mu \mathrm{L}$ aliquot from each dilution $\left(10^{1}-10^{7}\right)$ was added to 200

$235 \mu \mathrm{L}$ of either R2A or MM2TS in 96 well microtitre plates. Following 2 weeks of growth in an Innova Incubator Shaker Series (New Brunwick Scientific, UK) at $75 \mathrm{rpm}$ and 25 ${ }^{\circ} \mathrm{C}$, the OD (590 nm) was recorded after 3 minutes shaking (Intensity Level 3) using an ELX808IU spectrophotometer (Bio Tek Instruments Inc., Winooski, VT). The OD590 was used to identify the lowest dilution with growth in all five wells, the number of wells with

240 growth in the subsequent two dilutions was used to generate a three digit MPN number and this was used to refer to an MPN table to obtain an MPN g ${ }^{-1}$ value (FDA, 2011). This MPN g ${ }^{-1}$ value was substituted into the following equation: $\mathrm{MPN}^{-1} \times(1 / \mathrm{V}) \times(\mathrm{DF}) . \mathrm{V}$ is the volume plated in $\mathrm{mL}$ and $\mathrm{DF}$ is the dilution factor $(0.02 \mathrm{~mL}$ and 20 , respectively for this experiment).

245 In order to ascertain the taxonomic diversity of sulfonate mobilisers, a $100 \mu \mathrm{L}$ aliquot of bacterial suspension was removed from 3 wells of the liquid MM2TS for the control and each treatment and spread on solid MM2TS under aseptic conditions (Beil et al. 1995) using $6 \mathrm{~g} \mathrm{~L}^{-1}$ of low-S agarose as solidifying agent. After one week, 20 single colonies were selected and sub-cultured for each plant type and treatment. DNA was extracted 250 from each isolate using the quick lysis protocol (Schmalenberger et al., 2001) and 16S 
rRNA gene amplification was undertaken with a final concentration per $25 \mu \mathrm{L}$ reaction of $1 \mathrm{X}$ buffer $(2 \mathrm{mM} \mathrm{MgCl} 2), 0.2 \mathrm{mM}$ dNTP mix, $0.4 \mu \mathrm{mol}$ of each primer 27F and $1492 \mathrm{R}$ (Lane, 1991) (Table 1) and 0.5 U of DreamTaq polymerase (Fisher Scientific, Waltham, MA). All PCR reactions were carried out in a G-Storm GS2 thermocycler (G-Storm, UK).

255 The cycling conditions were as follows; initial denaturation of $95^{\circ} \mathrm{C}$ for $5 \mathrm{~min}, 32$ cycles of $94{ }^{\circ} \mathrm{C}$ denaturation (45 s), $55^{\circ} \mathrm{C}$ annealing (45 s) and $72{ }^{\circ} \mathrm{C}$ extension (90 s). Final extension was undertaken at $72{ }^{\circ} \mathrm{C}$ for $5 \mathrm{~min}$.

To identify dominant OTUs (Operational Taxonomical Units), RFLP (Restriction Fragment Length Polymorphism) was carried out on PCR amplicons using the restriction 260 enzymes $R s a \mathrm{I}$ and $\operatorname{Taq} \mathrm{I}\left(5 \mathrm{U}\right.$ per reaction; Thermo Scientific) for $4.5 \mathrm{~h}$ at $37{ }^{\circ} \mathrm{C}$. The digested DNA was run on a 2\% agarose gel at $100 \mathrm{~V}$ for $40 \mathrm{~min}$. Dominating OTUs were screened for presence of the sulfonate mobilising asfA gene using the functional asfA primers asfAF2 and asfBtoA (Schmalenberger and Kertesz 2007) (Table 1). The asfA gene was amplified using the following PCR protocol; initial denaturation of $94{ }^{\circ} \mathrm{C}$ for 4 265 min, 10 cycles of $94{ }^{\circ} \mathrm{C}$ denaturation (45 s), $67-57{ }^{\circ} \mathrm{C}$ touchdown $(30 \mathrm{~s})$, and extension of $72{ }^{\circ} \mathrm{C}(90 \mathrm{~s})$, plus 25 further cycles at with an annealing temperature of $55^{\circ} \mathrm{C}$. The PCR was conducted using a Kapa 2G Robust PCR kit (Kapa Biosystems, Woburn, MA, USA) in $25 \mu \mathrm{L}$ reactions containing; 1 x Buffer A, 1 x Enhancer, 5\% DMSO (SigmaAldrich), $2 \mathrm{mM} \mathrm{MgCl} 2,0.2 \mathrm{mM} \mathrm{dNTP}, 0.5 \mu \mathrm{M}$ of each primer and $0.5 \mathrm{U}$ of the Kapa 270 Robust polymerase.

Subsequently, amplified 16S and asfA genes of dominant OTUs were purified (GenElute, Sigma-Aldrich, St. Louis, MO) and quantified using a Nano Drop ND-1000 (Thermo Scientific, Waltman, MA, USA) before being subjected to Sanger sequencing (GATC Biotech, Germany) (Sanger and Coulson 1975). 
Following a 10-week growth period, the PGP pot experiments were harvested. An indepth morphological assessment was used to pick $0.5 \mathrm{~g}$ of hyphae from the roots of $A$. stolonifera for the control, and the three inoculation treatments (AC, Glomus and Mixed) using a compound microscope (x 100 magnification) (Hodge \& Fitter, 2010). Bacteria were extracted and MPN analysis was undertaken in MM2TS media as described above. Additionally, at the time of harvest all above and below ground plant material was dried at $55{ }^{\circ} \mathrm{C}$ for $72 \mathrm{~h}$ in a fan assisted oven (Carbolite, UK) after which the dry weights were recorded. All excess soil was removed from the roots using a fine bristled brush before drying.

\subsection{Community fingerprinting}

Community fingerprinting analysis was undertaken for the bi-compartmental microcosm experiments. The frozen pellets of the bacterial extractions were used for community DNA extractions using the UltraClean Soil DNA extraction kit from MoBio (Carlsbad, CA). The extracted DNA was used for PCR-DGGE of bacterial 16S rRNA and Fungal 290 ITS communities for the bi-compartmental microcosms.

Bacterial 16S rRNA gene amplification was carried out using the primer pair GC341F/518R (Table 1) targeting the V3 region for DGGE (Muyzer et al., 1993). The final concentration in each $25 \mu \mathrm{L}$ reaction was; $1 \mathrm{X}$ buffer $(2 \mathrm{mM} \mathrm{MgCl} 2), 0.2 \mathrm{mM}$ dNTP mix, $0.4 \mu \mathrm{mol}$ of each primer and $0.5 \mathrm{U}$ of DreamTaq polymerase (Fisher Scientific, Waltham,

295 MA). A touchdown PCR protocol was used with the following cycling conditions; initial denaturation of $95{ }^{\circ} \mathrm{C}$ for $5 \mathrm{~min}, 20$ cycles of $94{ }^{\circ} \mathrm{C}$ denaturation $(45 \mathrm{~s}), 65-55{ }^{\circ} \mathrm{C}$ touchdown (45 s), $72{ }^{\circ} \mathrm{C}$ extension (45 s), plus 18 further cycles with an annealing 
temperature of $55{ }^{\circ} \mathrm{C}$. Final extension was undertaken at $72{ }^{\circ} \mathrm{C}$ for $5 \mathrm{~min}$. DGGE was carried out on 200 x 200 x 1 mm gels in a TV400 DGGE apparatus (Scie-Plas, Cambridge,

$300 \mathrm{UK})$. Gels of $10 \%$ (w/v) acrylamide/bisacrylamide were prepared and run using a linear $30-60 \%$ gradient in $1 \times$ TAE buffer $\left(60^{\circ} \mathrm{C}\right)$ for $16.5 \mathrm{~h}$ at $63 \mathrm{~V}$ (Fox et al., 2014). After completion, gels were stained in SYBR Gold (1:10,000 diluted) (Invitrogen, Carlsbad, CA) for 30 min and the image taken on a Syngene G:Box (Cambridge, UK).

Fungal DNA fingerprinting was undertaken using the fungal specific primer ITS-1F

305 (Gardes \& Bruns, 1993) and ITS-4 (White et al., 1990) (Table 1). This product was tenfold diluted and used as template in a nested PCR using the primer pair ITS-1FGC (Bougoure \& Cairney, 2005) and ITS-2 (White et al., 1990) (Table 6). Both PCRs were undertaken in $25 \mu \mathrm{L}$ reactions each containing; $1 \mathrm{X}$ buffer $(2 \mathrm{mM} \mathrm{MgCl}$ ), $1 \mathrm{M}$ betaine, $0.2 \mathrm{mM}$ dNTP mix, $0.4 \mu \mathrm{mol}$ of each primer and $0.5 \mathrm{U}$ of DreamTaq polymerase (Fisher

310 Scientific, Waltham, MA). For both PCR reactions, amplification was performed as follows: initial denaturation of $95^{\circ} \mathrm{C}$ for $5 \mathrm{~min}, 40$ cycles at $95^{\circ} \mathrm{C}$ denaturation $(45 \mathrm{~s}), 60$ ${ }^{\circ} \mathrm{C}$ annealing (45 s) and $72{ }^{\circ} \mathrm{C}$ extension (45 s), and 20 further cycles with an annealing temperature of $50{ }^{\circ} \mathrm{C}$ (Gardes \& Bruns, 1993). Final extension was undertaken at $72{ }^{\circ} \mathrm{C}$ for 5 min. DGGE was run as before with a gradient of $35-65 \%$.

\subsection{Diversity of AM fungi and AsfA}

$\mathrm{AM}$ and asfA gene diversity was analysed by generating a clone library of the Control, Glomus and Mixed treatment of L. perenne. For AM fungal diversity, the AM specific primer AM1 (Helgason et al., 1998) alongside the universal eukaryotic primer NS31

320 (Simon et al., 1992) (Table 1) were used to target the AM fungal 18S rRNA gene. The 
final concentration per $25 \mu \mathrm{L}$ PCR reaction was; $1 \mathrm{X}$ buffer $(2 \mathrm{mM} \mathrm{MgCl}), 1 \mathrm{M}$ betaine, $0.2 \mathrm{mM}$ dNTP mix, $0.4 \mu \mathrm{mol}$ of each primer and $0.5 \mathrm{U}$ of DreamTaq polymerase (Fermentas, Waltman, MA). The PCR was carried out under the following conditions; initial denaturation of $95{ }^{\circ} \mathrm{C}$ for $5 \mathrm{~min}, 30$ cycles of $94{ }^{\circ} \mathrm{C}$ denaturation $(30 \mathrm{~s}), 58{ }^{\circ} \mathrm{C}$ 325 annealing (60 s) and $72{ }^{\circ} \mathrm{C}$ extension (90 s). Final extension was undertaken at $72{ }^{\circ} \mathrm{C}$ for 5 min.

For diversity of sulfonate mobilising bacteria, the asfA gene was amplified with primers asfAF1all (Gahan \& Schmalenberger, 2015) and asfBtoA (Schmalenberger \& Kertesz, 2007) (Table 1). A touchdown PCR was carried out under the following conditions; initial 330 denaturation of $95{ }^{\circ} \mathrm{C}$ for $5 \mathrm{~min}, 10$ cycles of $95{ }^{\circ} \mathrm{C}$ denaturation $(30 \mathrm{~s}), 65-55^{\circ} \mathrm{C}$ touchdown (30 s) and $68{ }^{\circ} \mathrm{C}$ extension (40 s), and 25 further cycles at $55^{\circ} \mathrm{C}$ annealing. Final extension was undertaken at $68{ }^{\circ} \mathrm{C}$ for $5 \mathrm{~min}$. PCR was formulated in $25 \mu \mathrm{L}$ reactions each containing; $1 \mathrm{X}$ Terra PCR Direct Buffer $(2 \mathrm{mM} \mathrm{MgCl} 2), 0.2 \mathrm{mM}$ dNTP mix, $0.4 \mu \mathrm{mol}$ of each primer and 0.7 U of Terra PCR Direct Polymerase (ClonTech 335 Europe, Saint-Germain-en-Laye, France).

The respective PCR products were purified, quantified (see above) and ligated into the cloning vector pJET1.2/blunt (CloneJet, Thermo Scientific). The respective ligation reaction was transformed into E. coli DH5 $\alpha$. To ascertain taxonomic diversity of recombinant plasmids containing an insert of the correct size, RFLP was carried out on 340 PCR amplicons using 10U of the restriction enzymes AluI and RsaI (Thermo Scientific) in the provided buffer overnight. Clones with matching restriction patterns were classified as a single genotype (OTU) using Phoretix 1D software (Nonlinear Dynamics, Newcastle upon Tyne, UK). Unique genotypes with more than one representative clone were reamplified and the purified PCR product was used for sequence identification (GATC 
345 Biotech). The sequences obtained were subjected to gene comparison using BLAST (Altschul et al., 1990). Sequences of asfA were imported into arb (Version 5.2) (Ludwig et al., 2004), translated into proteins and integrated into an asfA phylogenetic tree (Schmalenberger et al., 2010). 
Table 1 - Primers used in this study

\begin{tabular}{|c|c|c|c|}
\hline ID & Sequence & Target & Reference \\
\hline $341 \mathrm{~F}-\mathrm{GC}$ & $\begin{array}{l}\text { 5'CGCCCGCCGCGCGCGGCGGGCGGGGCGGGGGCACGGGGGGCCTCGGGACC } \\
\text { GAGCAG-3' }\end{array}$ & 16S rRNA & Muyzer et al. 1993 \\
\hline AsfAF2 & 5'-TACATGCGSCTGATGCGCA-3' & asfA gene & $\begin{array}{l}\text { Schmalenberger and } \\
\text { Kertesz } 2007\end{array}$ \\
\hline AsfBtoA & 5'-ASCTCGCACATGAAGCAGG-3' & asfA gene & $\begin{array}{l}\text { Schmalenberger and } \\
\text { Kertesz } 2007\end{array}$ \\
\hline ITS-IF & 5'-CTTGGTCTTTAGAGGAAGTAA-3' & ITS fungal & $\begin{array}{l}\text { Gardes and Bruns } \\
1993\end{array}$ \\
\hline ITS-4 & 5'-TCCTCCGCTTATTGATATGC-3' & ITS fungal & White et al. 1990 \\
\hline ITS-IFGC & $\begin{array}{l}\text { 5'CGCCCGCCGCGCGCGGCGGGCGGGGCGGGGGCGCGGGGGCCTTGGTCTTTA } \\
\text { 'GAGGAAGTAA-3' }\end{array}$ & ITS fungal & $\begin{array}{l}\text { Bougoure and Cairney } \\
2005\end{array}$ \\
\hline ITS2 & 5'-GCTGCGTTCTTCATCGATGC-3' & ITS fungal & White et al. 1990 \\
\hline
\end{tabular}




\section{2.7. Data analysis}

354 Univariate analysis of MPN, root colonisation and PGP data was carried out using SPSS

355 (Version 22.0; IBM, USA). DGGE fingerprinting gels were digitalised and band patterns

356 analysed with the software package Phoretix 1D (Nonlinear Dynamics, UK). Cluster

357 analysis via UPGMA was carried out and obtained band pattern matrices were exported

358 for DCA and permutation tests (Monte-Carlo with 9,999 replicates) as described 359 previously (Schmalenberger et al., 2010). 


\section{3. Results}

361 3.1. PGP effect of inoculation with AM fungi

362 Following a 10 week growth period in pots, there was an increase in the aboveground dry

363 weight of plants inoculated with the Mixed, Glomus and Control-AC over the Control

364 treatment $(P<0.05)$ (Figure 3). Additionally, Mixed treatment had increased

365 aboveground dry weight over the Glomus and Control-AC $(P<0.05)$. There was not a

366 difference between Glomus and Control-AC $(P>0.05)$. The increased aboveground

367 biomass obtained with the Glomus treatment was attributed to the presence of the AM

368 fungus, whereas, the Control-AC inoculum contained commercial additives that may

369 have led to the increased biomass obtained over the control. Mixed treatment had the

370 largest mean aboveground dry weight $(1.24 \pm 0.05 \mathrm{~g})$ and the Control experiment had the

371 lowest mean aboveground dry weight of $(0.90 \pm 0.06 \mathrm{~g})$ (Figure 3A).

372 The belowground dry weight was analysed and increased root/hyphae biomass was

373 observed for Mixed over the Glomus treatment and controls $(P<0.05)$ (Figure 3). There

374 was not a difference in biomass for the Control, Control-AC or Glomus treatments $(P>$

375 0.05). Mixed treatment had the largest mean belowground dry weight at $2.37 \mathrm{~g}$, while the

376 remaining experiments had a mean dry weight of 1.71 to $1.97 \pm 0.18 \mathrm{~g}$ (Figure 3B). 


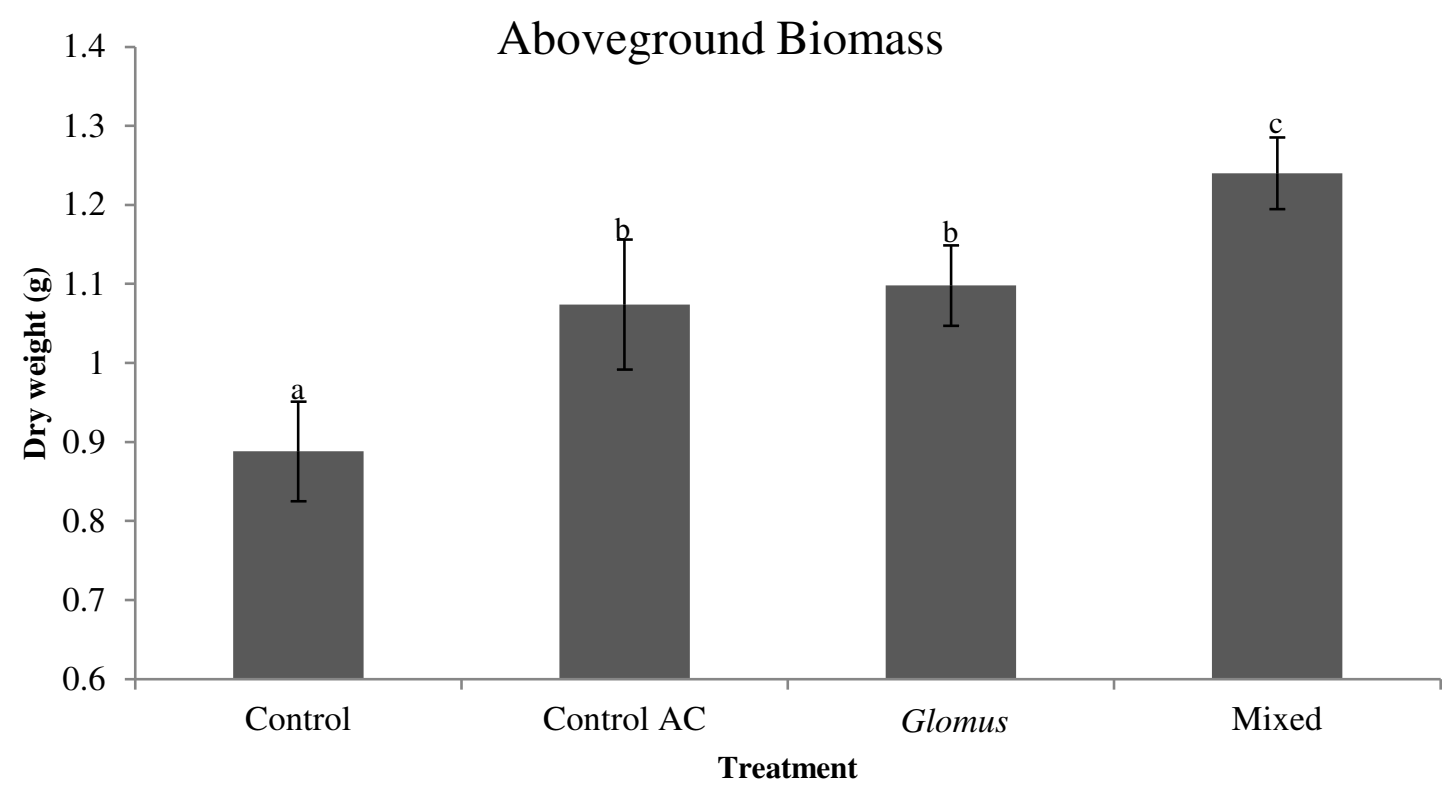

378 Figure 3A - Comparison of the dry weight of Agrostis stolonifera aboveground biomass. Control = 379 free of inoculant, Control $\mathbf{A C}=$ autoclaved inoculum, Glomus $=$ R. irregularis inoculum, Mixed $=$ mixed inoculum. Letters (a-c) indicate significant differences.

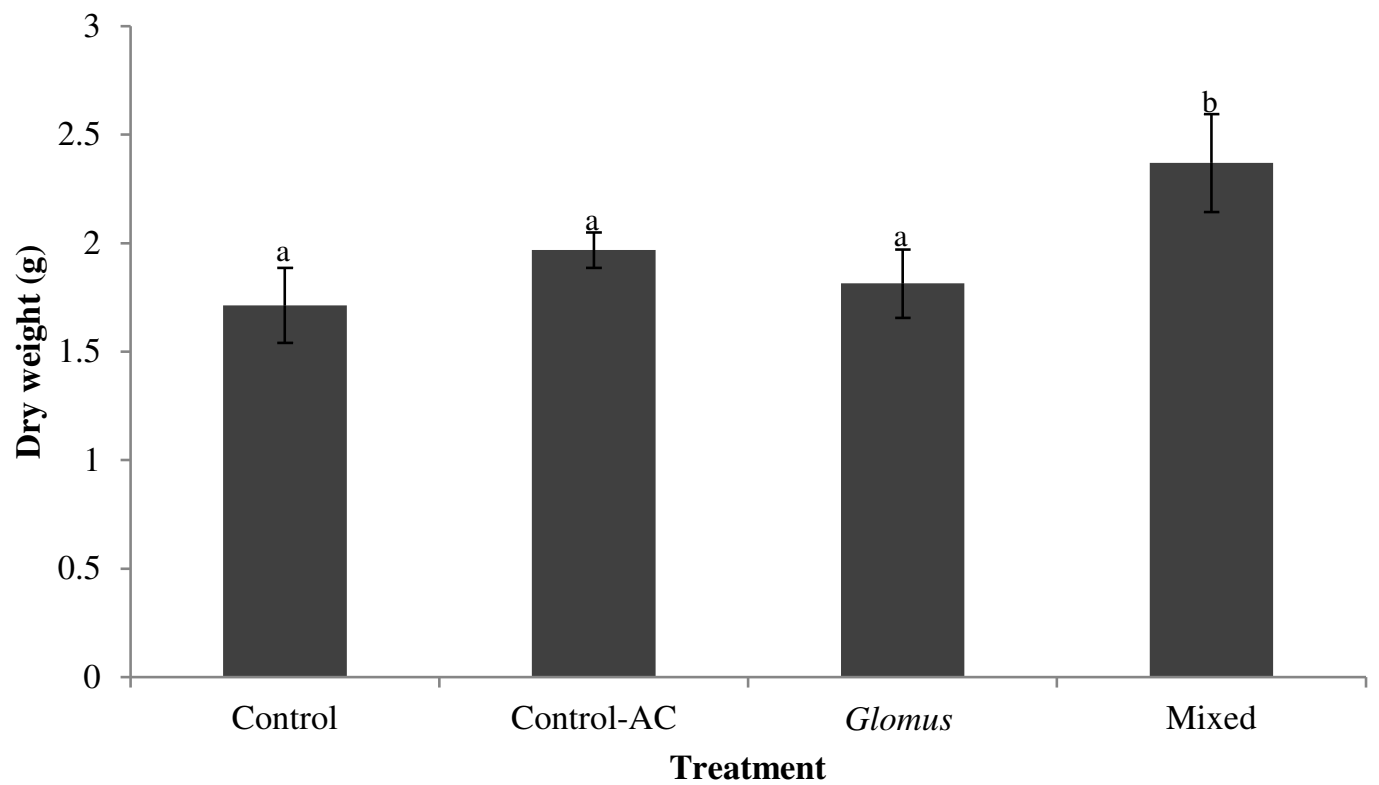

Figure 3B - Comparison of the dry weight of Agrostis stolonifera belowground biomass. Control = free of inoculant, Control-AC $=$ autoclaved inoculum, Glomus $=$ R. irregularisinoculum, Mixed $=$ mixed inoculum. Letters (a-b) indicate significant differences. 
390 For all three plants, intracellular AC and VC increased following both the Glomus and

391 Mixed treatment over the $C$ treatment $(P<0.05)$ (Figure 4). Additionally, there was an

392 increase in AC following Mixed over Glomus treatment for L. perenne and A. stolonifera

$393(P<0.05)$ (Figure 5A, B), this effect was not observed for $P$. lanceolata $(P>0.05)$ (Figure

394 4C). There was not an additional increase in VC with Mixed over Glomus treatment for

395 the three plants analysed $(P>0.05)$. Finally, there was not an effect of AM inoculation

396 on HC $(P>0.05)$ due to the presence of dense networks of hyphal mycelia surrounding

397 the plant root which made it difficult to identify points of infection (Figure 4). 

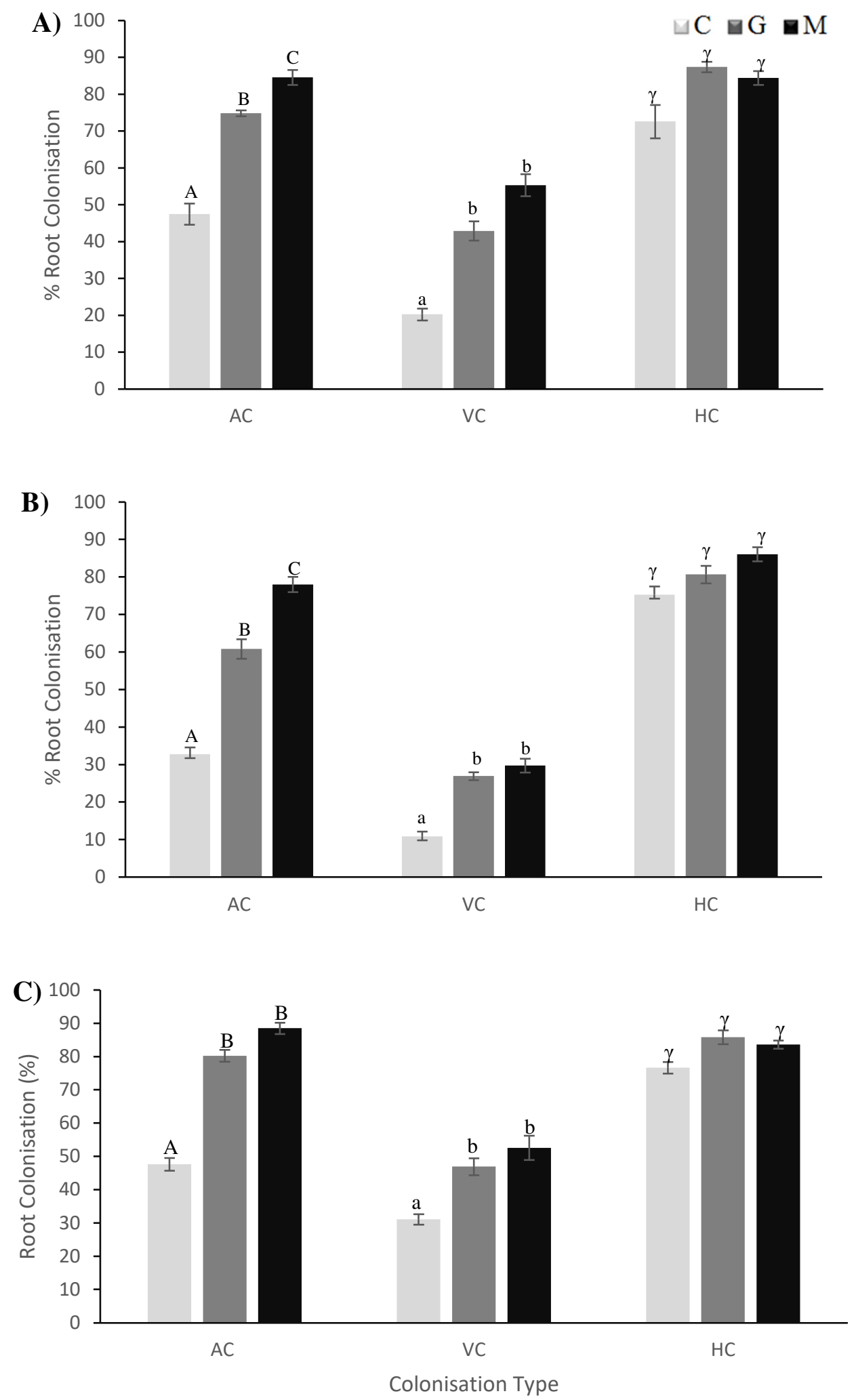

401 Figure 4 - Arbuscular mycorrhizal root colonisation for Lolium perenne (A), Agrostis stolonifera (B) 402 and Plantago lanceolata $(\mathbf{C})$. Arbuscular colonisation = AC, vesicular colonisation = VC, and hyphal 403 colonisation $=$ HC. Treatments include Control $=\mathbf{C}$, Glomus $=\mathbf{G}(\boldsymbol{R}$. irregularis inoculum $)$, and Mixed 404 = M (6 AMF species inoculumn). Letters (A-B, a-b, $\gamma)$ indicate significant differences. 
406 The PGP pot experiments demonstrated similar colonisation rates and sensitivity to AM

407 species as was observed with the bi-compartmental microcosms. Arbuscular colonisation

408 was increased following both Glomus and Mixed inoculation over the Control and the

409 Control-AC treatments $(P<0.05)$. There was not an increase in colonisation rate with

410 Mixed over Glomus inoculations or Control-AC over the un-inoculated Control $(P>0.05)$

411 (Figure 5).

412 Colonisation rates were $16 \%$ and $20 \%$ for control and Control-AC whereas for Glomus

413 and Mixed treatment the colonisation rate was $68 \%$ and $80 \%$, respectively (Figure 5).

414 This result indicates that inoculation with active AM inocula increased colonisation 415 capacity.

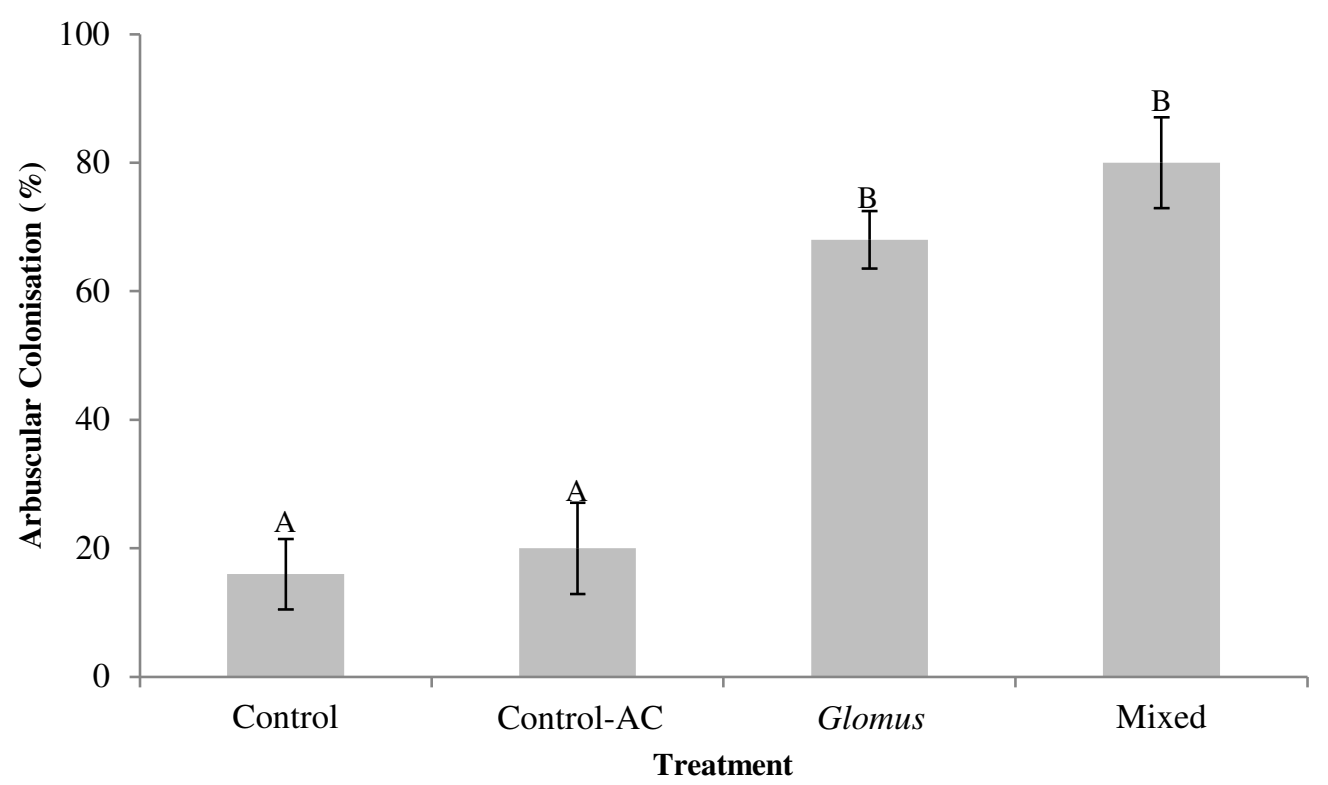

418 Figure 5 - Arbuscular mycorrhizal root colonisation for Plant Growth Promotion (PGP) pot 419 experiments with Agrostis stolonifera. Control $=$ free of inoculant, Control-AC $=$ autoclaved 420 inoculum, Glomus $=R$. irregularis inoculum, Mixed = AM mix inoculum. Letters (A-B) indicate 421 significant differences. 


\section{3.3. Quantification of cultivable heterotrophic microbes}

\section{3.3.1 Bi-compartmental microcosms}

425 For all plants, more abundant bacterial communities were observed in R2A and MM2TS

426 media for picked hyphae (Control, Glomus, and Mixed) over untreated bulk soil $(P<$

427 0.01) (Figure 6). Additionally, higher abundances were observed with Mixed and Glomus

428 treatment over the Control experiment for L. perenne and P. lanceolata, respectively $(P$

$429<0.05)$ (Figure 6A, C). However, an additional increase in abundance of either the total

430 cultivable heterotrophic or the sulfonate mobilising bacterial community was not

431 observed between Mixed and Glomus treatment $(P>0.05)$ (Figure 6A, C). For $A$.

432 stolonifera, there was not an increase in abundance of either the total cultivable

433 heterotrophic or the sulfonate mobilising bacterial community with Mixed or Glomus

434 treatment over the Control experiment $(P>0.05)$ (Figure 6B, C). However, the total

435 cultivable heterotrophic and the sulfonate mobilising bacterial communities were more

436 abundant for picked hyphae and bulk soil for A. stolonifera and P. lanceolata over $L$.

437 perenne (Figure 6). For L. perenne, growth from bulk soil was below the detection limit

438 in MM2TS (1000 MPN g ${ }^{-1}$ ) (Figure 6A), while for A. stolonifera and P. lanceolata, it

439 ranged from $10^{3}-10^{4} \mathrm{MPN} \mathrm{g}^{-1}$ suggesting a higher indigenous community in these plant

440 microcosms (Figure 6B, C). 

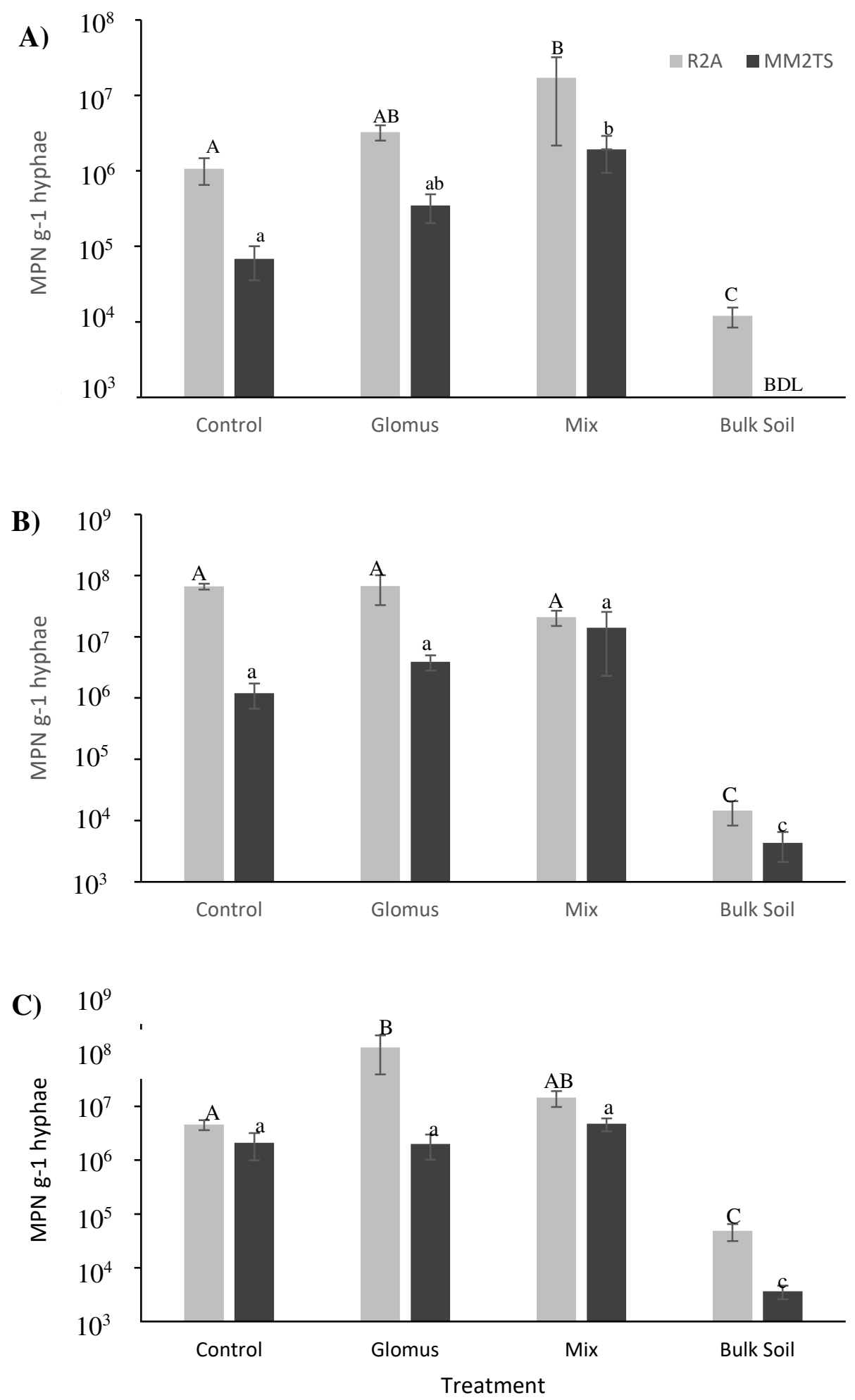

444 Figure 6 - Most probable number (MPN) analysis of bacteria in microcosms with Lolium perenne 445 (A), Agrostis stolonifera (B) and Plantago lanceolata (C). R2A and MM2TS were used to quantify the 446 total cultivable bacterial community and sulfonate mobilisers, respectively. Control = free of 447 inoculant, Glomus $=\boldsymbol{R}$. irregularis inoculum, Mixed = AM mix inoculum, Bulk Soil = untreated soil. Letters (A-B-C, a-b-c) indicate significant differences. Below detection limit = BDL. 
451 For the PGP pot experiment, as observed for the microcosms, the sulfonate mobilising

452 bacterial community abundance was higher for the picked hyphae over the bulk soil $(P<$

453 0.05) (Figure 7). For the pot experiments unlike the microcosms, a higher abundance of

454 sulfonate mobilisers were observed for both Glomus and Mixed treatments over both the

455 Control and the Control-AC (autoclaved inoculum) treatment $(P \leq 0.05)$ (Figure 7). A

456 difference was not observed between both controls, or between both AMF treatments ( $P$

$457>0.05)$. Differences between the results obtained for the pot experiments and bi458 compartmental microcosms can be attributed to their set-up (pot versus microcosm) and 459 growth period (10 weeks versus 6 months).

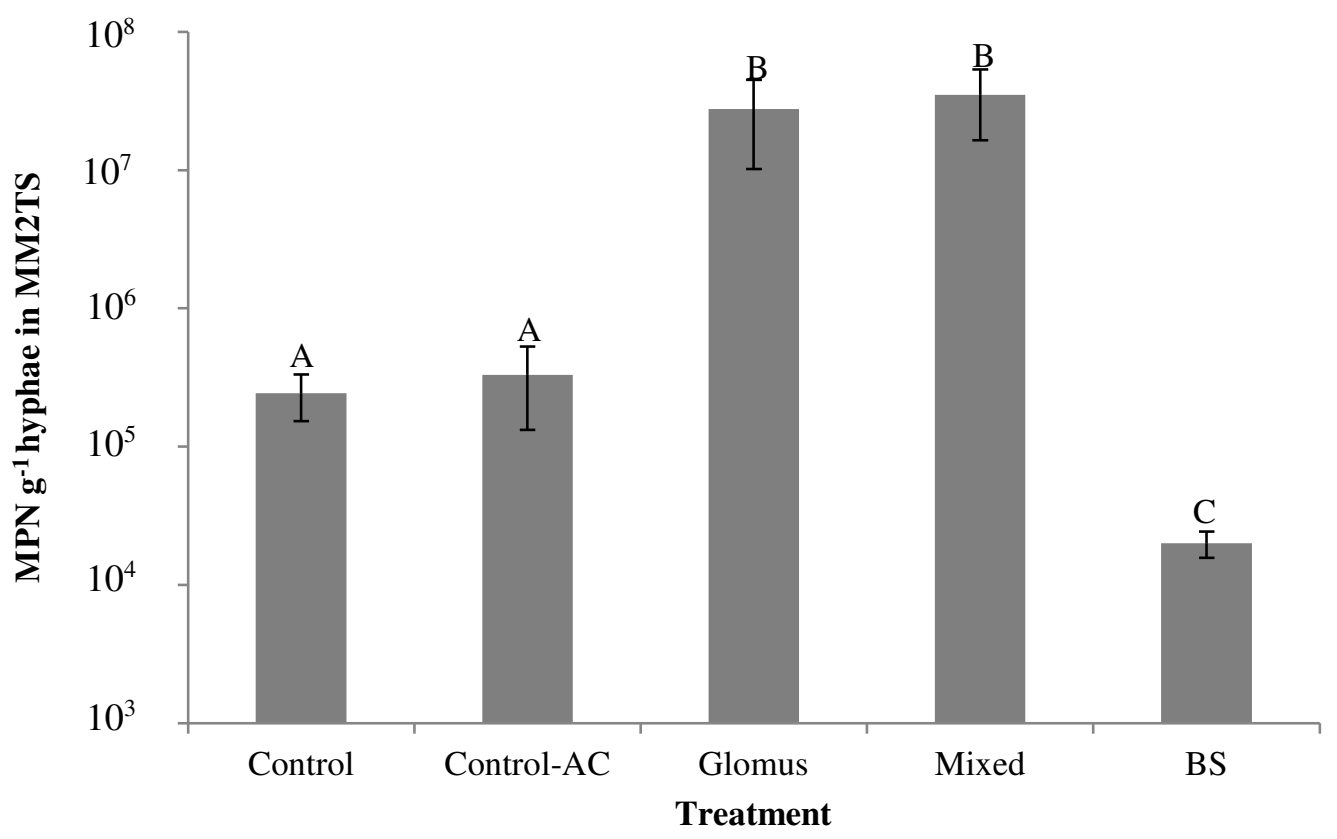

462 Figure 7 - Most probable number (MPN) analysis of the bacterial community in the plant growth 463 promotion pot experiment with Agrostis stolonifera. MM2TS were used to quantify the cultivable 464 sulfonate mobilising community. Control = free of inoculant, Control-AC $=$ autoclaved inoculum, 465 Glomus $=$ R. irregularis inoculum and Mixed $=$ AM mix inoculum, Bulk Soil $=$ untreated soil. Letters 466 (A-C) indicate significant differences. 
468 For the 60 isolates taken from the Control, 9 OTUs were obtained in total (based on 16S

469 rRNA gene typing). Of these, 3 were found in L. perenne, and 5 in A. stolonifera and $P$.

470 lanceolata respectively. Two of these OTUs (OTUs 1 and OTU3) were discovered in all

471 three plants and were present in both the Control and the AMF treatments (Table 2),

472 suggesting that they are common hyphosphere sulfonate mobilisers. The remaining OTUs

473 (OTUs 2, 11, 12, 13, 23, 24, and 25) were present only in the Control experiment and

474 only associated with one of the three plants (Table 2). This result suggests that inoculated

475 soil harbours a distinct community of sulfonate mobilising bacteria.

476 For the 60 isolates taken from the Glomus treatment, 8 OTUs were obtained. Of these, 4

477 were recovered from L. perenne (OTUs 4, 5, 6, and 7), 6 from A. stolonifera (OTUs 1, 4,

$4786,15,26$ and 27), and 5 from P. lanceolata (OTUs 1, 4, 5, 6, and 15), respectively. The

479 OTUs 7, 26 and 27 were specific to one of the three plants and the Glomus treatment

480 (Table 2). The remainder of the OTUs overlapped across experiments and plants;

481 however, OTUs 4, 5, 6, and 15 were only present following inoculation in the Glomus or

482 Mixed treatments (Table 2).

483 For the Mixed treatment, 19 OTUs were obtained. Of these, 6 were obtained from $L$.

484 perenne, and 7 and 12 from A. stolonifera and P. lanceolata, respectively. The OTUs 1 ,

$4853,4,5,6$ and 15 were present for more than one plant and more than one experiment

486 (Table 2). There was minimal overlap of OTUs across Control, Glomus and Mixed

487 experiments suggesting that each treatment harbours a distinct cultivable sulfonate

488 mobilising community (Table 2). OTUs 1 and 3 overlapped with the Control experiment,

489 while OTUs $4,5,6$, and 15 overlapped with the Glomus treatment. The remaining 13

490 OTUs were exclusive to the Mixed treatment (OTUs 8, 9, 10, 14, 16, 17, 18, 19, 20, 21, 
491 22, 28, and 29). Additionally, the Mixed treatment had a higher number of OTUs than

492 Control and Glomus experiments combined (19 compared to 9 and 8 for Control and

493 Glomus, respectively) suggestive of a higher diversity of sulfonate mobilisers following

494 this inoculation treatment.

495 
Table 2 - Dominant Operational Taxonomic Units (OTUs) of bacteria extracted from the AM hyphae of Agrostis stolonifera (Agrostis), Lolium perenne (Lolium), and Plantago lanceolata (Plantago) either un-inoculated (Control), inoculated with $R$. iregularis (Glomus), or inoculated with a mix of 6 arbuscular mycorrhizal fungi (Mixed). Symbols mean OTU occurred in either $*=$ all plants, $\uparrow=$ all 500 treatments, $\alpha=$ Control, $\beta=$ Glomus, or $\gamma=$ Mixed.

\begin{tabular}{|c|c|c|c|c|c|c|c|}
\hline \multirow{2}{*}{$\begin{array}{c}\text { OTU } \\
\text { ID }\end{array}$} & \multicolumn{3}{|c|}{ Isolation Source } & \multicolumn{3}{|c|}{ Occurrence per Treatment (\%) } & \multirow{2}{*}{$\begin{array}{c}\text { Community } \\
(\%)\end{array}$} \\
\hline & Lolium & Agrostis & Plantago & Control & Glomus & Mixed & \\
\hline $1^{*+}$ & $\checkmark$ & $\checkmark$ & $\checkmark$ & 55 & 12 & 17 & 25 \\
\hline $2^{\alpha}$ & $\checkmark$ & & & 8 & & & 3 \\
\hline $3 * a \gamma$ & $\checkmark$ & $\checkmark$ & $\checkmark$ & 23 & & 7 & 9 \\
\hline $4 * \beta \gamma$ & $\checkmark$ & $\checkmark$ & $\checkmark$ & & 30 & 10 & 13 \\
\hline $5^{* \beta \gamma}$ & $\checkmark$ & $\checkmark$ & $\checkmark$ & & 15 & 20 & 12 \\
\hline $6 * \beta \gamma$ & $\checkmark$ & $\checkmark$ & $\checkmark$ & & 23 & 3 & 9 \\
\hline $7^{\beta}$ & $\checkmark$ & & & & 7 & & 2 \\
\hline $8^{\gamma}$ & $\checkmark$ & & & & & 12 & 4 \\
\hline $9^{\gamma}$ & $\checkmark$ & & & & & 7 & 2 \\
\hline $10^{\gamma}$ & $\checkmark$ & & & & & 3 & 1 \\
\hline $11^{\alpha}$ & & & $\checkmark$ & 3 & & & 1 \\
\hline $12^{\alpha}$ & & & $\checkmark$ & 3 & & & 1 \\
\hline $13^{a}$ & & & $\checkmark$ & 2 & & & 1 \\
\hline $14^{\beta}$ & & & $\checkmark$ & & & 5 & 1.5 \\
\hline $15^{\beta \gamma}$ & & $\checkmark$ & $\checkmark$ & & 5 & 7 & 3.5 \\
\hline $16^{\gamma}$ & & & $\checkmark$ & & & 2 & 1 \\
\hline $17^{\gamma}$ & & & $\checkmark$ & & & 2 & 1 \\
\hline $18^{\gamma}$ & & & $\checkmark$ & & & 2 & 1 \\
\hline $19^{\gamma}$ & & & $\checkmark$ & & & 2 & 1 \\
\hline $20^{\gamma}$ & & & $\checkmark$ & & & 2 & 1 \\
\hline $21^{\gamma}$ & & & $\checkmark$ & & & 2 & 1 \\
\hline $22^{\gamma}$ & & & $\checkmark$ & & & 2 & 1 \\
\hline $23^{a}$ & & $\checkmark$ & & 5 & & & 1.5 \\
\hline $24^{a}$ & & $\checkmark$ & & 3 & & & 1 \\
\hline $25^{\alpha}$ & & $\checkmark$ & & 3 & & & 1 \\
\hline $26^{\beta}$ & & $\checkmark$ & & & 5 & & 1.5 \\
\hline $27^{\beta}$ & & $\checkmark$ & & & 5 & & 1.5 \\
\hline $28^{\gamma}$ & & $\checkmark$ & & & & 2 & 1 \\
\hline $29^{\gamma}$ & & $\checkmark$ & & & & 2 & 1 \\
\hline
\end{tabular}


502 In order to ascertain the sulfonate mobilising functionality of dominant OTUs (see 3.4

503 above), screening for the presence of the desulfonating asfA gene was undertaken. Of 180

504 bacterial isolates, 29 different restriction patterns were obtained (Table 2), of these, 9

505 OTUs were cultured from the control $(\mathrm{C})$ experiment, 8 from the Glomus $(\mathrm{G})$ treatment

506 and 19 from mixed (M) treatment. Of the 9 control experiment OTUs, 2 overlapped with

507 Glomus and/or Mixed treatment and 7 OTUs were exclusive to the Control experiment.

508 Of the 8 Glomus treatment OTUs, 5 overlapped with Control and/or Mixed experiment

509 and 3 OTUs were exclusive to the Glomus treatment. Of the 19 Mixed treatment OTUs,

5106 overlapped with Control and/or Glomus experiment and 13 OTUs were exclusive to

511 Mixed treatment.

512 The dominant OTUs were then subjected to sequence identification and classes such as

513 Alphaproteobacteria, Betaproteobacteria, and the Actinobacteria predominated (Table

514 3). Variovorax was the dominating OTU at $25 \%$ of the sulfonate mobilising community

515 and was isolated in the hyphosphere of the Control and the AMF treatments (Table 3).

516 Paraburkholderia (13\%), Agrobacterium (12\%), Polaromonas (9\%), Rhodococcus (9\%),

517 and Mesorhizobium (4\%) were also prevalent desulfonating bacteria. Interestingly, while

518 Polaromonas (9\%) and Rhodococcus (9\%) have previously been shown to have

519 desulfonating ability, Paraburkholderia (13\%), Agrobacterium (12\%), and

520 Mesorhizobium (4\%) are newly associated with this capability. Furthermore, they were

521 only isolated from Glomus and/or Mixed microcosms (Table 3). All but OTU 6 and 8

522 (Rhodococcus and Mesorhizobium) were able to produce an amplification product in the

523 asfA PCR (see above). 
525 Table 3 - Dominant desulfonating Operational Taxonomic Units (OTUs) obtained from the AM hyphae of Agrostis stolonifera (Agrostis), Lolium perenne (Lolium), 526 and Plantago lanceolata (Plantago) either un-inoculated (Control), inoculated with $R$. irregularis (Glomus), or inoculated with a mix of 6 arbuscular mycorrhizal

527 fungi (Mixed). Isolates were screened for amplification of asfA PCR product (+/-)

Class affiliation Genus

OTU ID Isolate ID Closest Relative

Similarity \% Treatment Plant

Total asfA

$\%$

\begin{tabular}{|c|c|c|c|c|c|c|c|c|c|}
\hline Betaproteobacteria & Variovorax & OTU1 & $\mathrm{Ag}-\mathrm{C} 13$ & V. paradoxus & 100 & $\begin{array}{l}\text { Control, } \\
\text { Glomus, } \\
\text { Mixed }\end{array}$ & All & 25 & + \\
\hline Betaproteobacteria & Paraburkholderia & OTU4 & Pl-M10 & P. bryophila & 99 & $\begin{array}{l}\text { Glomus, } \\
\text { Mixed }\end{array}$ & All & 13 & + \\
\hline Alphaproteobacteria & Agrobacterium & OTU5 & Ag-G5 & A. rhizogenes & 99 & $\begin{array}{l}\text { Glomus, } \\
\text { Mixed }\end{array}$ & $\begin{array}{l}\text { Lolium, } \\
\text { Agrostis }\end{array}$ & 12 & + \\
\hline Betaproteobacteria & Polaromonas & OTU3 & Ag-C37 & P. rhizosphaerae & 99 & $\begin{array}{l}\text { Control, } \\
\text { Mixed }\end{array}$ & All & 9 & + \\
\hline Actinobacteria & Rhodococcus & OTU6 & $\mathrm{Pl}-\mathrm{C} 1$ & R. erythropolis & 100 & $\begin{array}{l}\text { Glomus, } \\
\text { Mixed }\end{array}$ & $\begin{array}{l}\text { Plantago, } \\
\text { Agrostis }\end{array}$ & 9 & - \\
\hline Alphaproteobacteria & Mesorhizobium & OTU8 & Lol-M17 & M. amorphae & 100 & Mixed & Lolium & 4 & - \\
\hline
\end{tabular}




\section{3.6. Community fingerprinting}

$530 \quad$ 3.6.1. $16 S$ rRNA community diversity

531 Community fingerprinting for L. perenne (Figure 8A) illustrated that there was a bacterial

532 community shift following both AMF inoculations (Glomus and Mixed) over the Control

533 experiment $(P<0.05)$. Additionally, there was a community shift following Mixed over

534 Glomus treatment $(P<0.05)$. The results show that the bacterial community of $L$. perenne

535 is sensitive to AMF symbiosis and shifts in response to both the Glomus and Mixed 536 treatment.

537 The bacterial community response of A. stolonifera (Figure 8B) illustrated a shift

538 following Mixed over Control experiment $(P<0.05)$. However, there was not a 539 community shift following Glomus over Control or Mixed over Glomus treatment $(P>$

540 0.05). The results show that the bacterial community of A. stolonifera is sensitive to AMF

541 symbiosis; however, this response is dependent on the species of AM fungi used for 542 inoculation.

543 The bacterial community of $P$. lanceolata (Figure 8C) demonstrated a community shift

544 to both AMF inoculations over the Control experiment $(P<0.05)$. However, there was 545 not an additional shift following Mixed over Glomus treatment $(P>0.05)$. The results 546 obtained for all three plants demonstrate a bacterial community response to AMF 547 inoculation; however, this response is dependent both on the species of AM fungi used to 548 inoculate and the suitability of the plant-AM fungal partnership. 

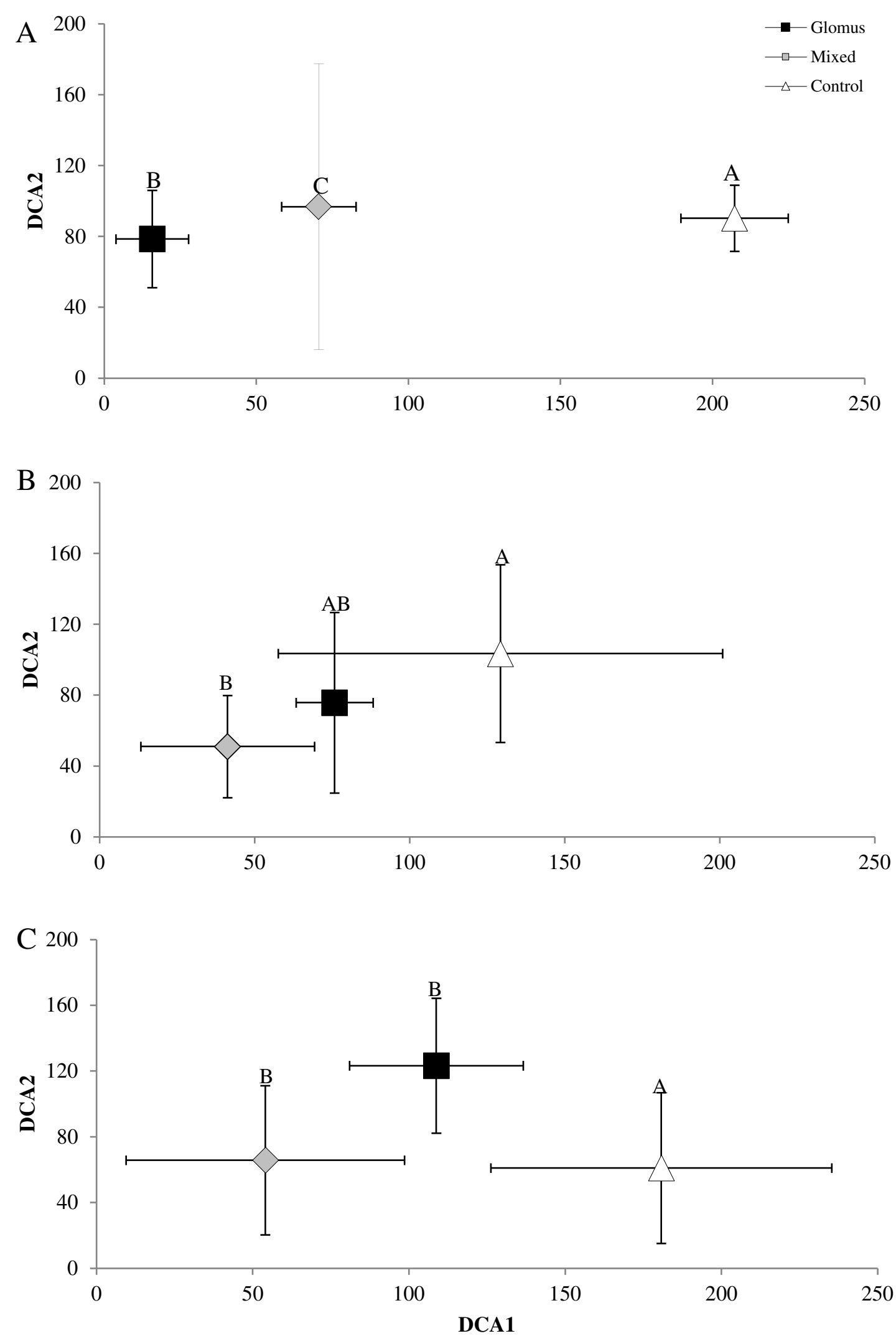

552 Figure 8 - Detrended correspondence analysis (DCA) bi-plot of the 16S bacterial rRNA community
553 fingerprint for Lolium perenne (A), Agrostis stolonifera (B) and Plantago lanceolata (C). DCA1 = Axis

554 1, DCA2 = Axis 2. Treatments; Control = Triangle, Glomus = Square, Mixed = Diamond. Letters (A555 B-C) indicate significant differences. 
557 Fungal community fingerprinting for L. perenne (Figure 9A) illustrated that there was a

558 community shift following inoculation with Glomus treatment over the Control

559 experiment $(P<0.05)$. However, there was not a fungal community shift following Mixed

560 over either Glomus treatment or the Control experiment $(P>0.05)$. Fungal community

561 fingerprinting for $A$. stolonifera and $P$. lanceolata (Figure 9B, C) illustrated that there

562 was a community shift following both AMF treatments over the Control experiment $(P<$

563 0.05). However, there was not a community shift following Mixed over Glomus treatment

$564(P>0.05)$

565 These results demonstrate that the fungal community in the hyphosphere shifts in 566 response to inoculation with AM fungi but that the response is not necessarily specific to

567 the species of AM fungi present i.e. in the mono species or six species inoculation. As the

568 current fingerprint approach includes both saprotrophic and mycorrhizal fungal species,

569 the presence of AMF bands may give rise to differences in the fungal community

570 composition present for the inoculation (Glomus and Mixed) treatments over the Control

571 experiment. 

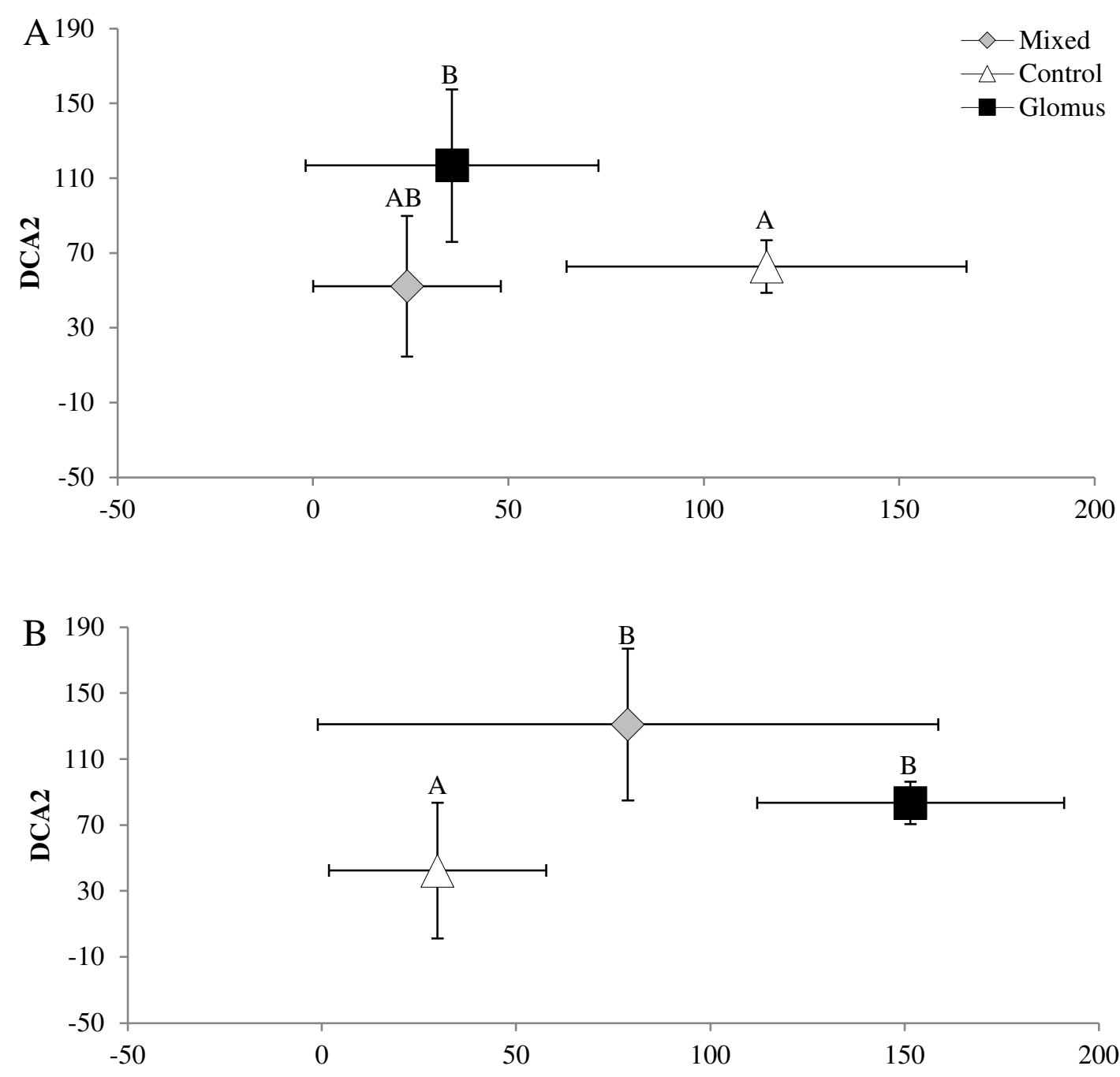

573

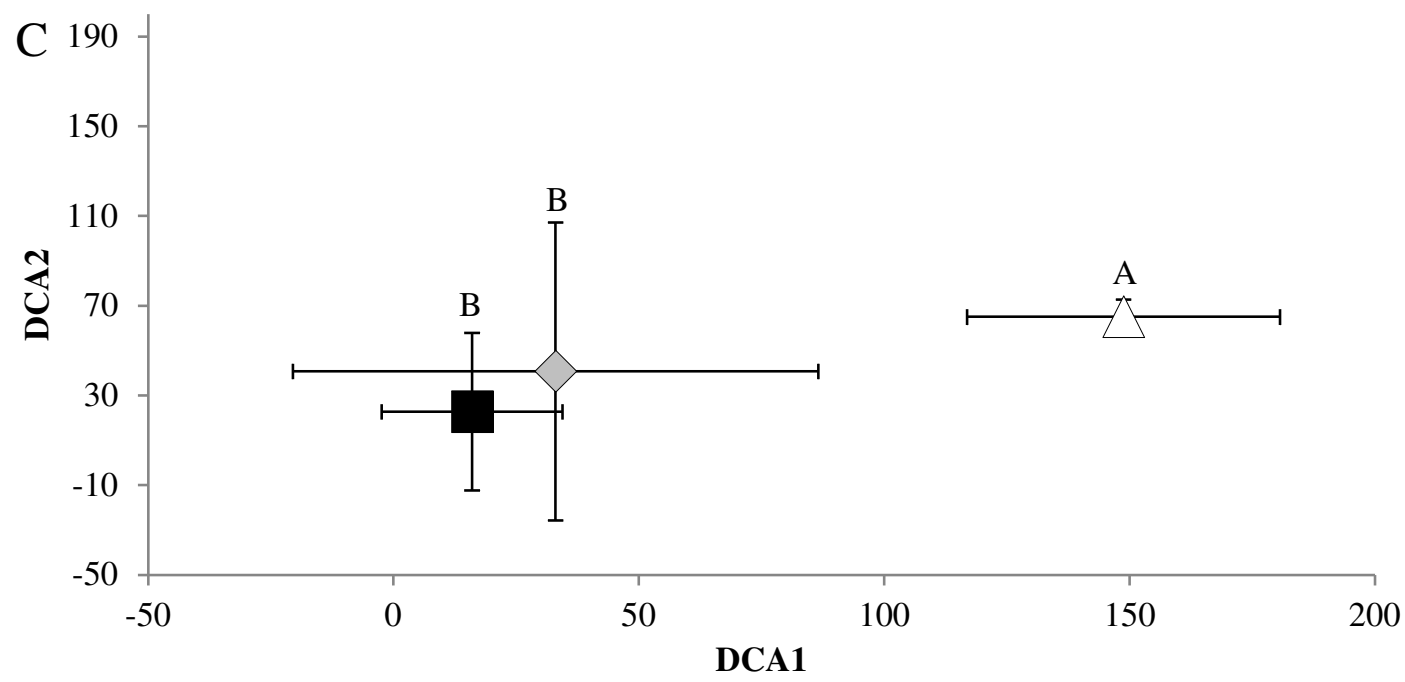

575 Figure 9 - Detrended correspondence analysis (DCA) bi-plot of the fungal ITS region community
576 fingerprint of Lolium perenne (A), Agrostis stolonifera (B) and Plantago lanceolata (C). DCA1 = Axis

577 1, DCA2 = Axis 2. Treatments; Control $=$ Triangle, Glomus $=$ Square, Mixed $=$ Diamond. Letters (A-

578 B) indicate significant differences. 
581 Clone libraries of AM fungal amplicons from the Glomus and Mixed treatments and the

582 Control experiment of L. perenne were screened for different OTUs via RFLP. Screening

583 of 150 clones (50 for each treatment) revealed 6 distinct OTUs with coverage of 100\%

584 for each library (Schmalenberger et al., 2007). There were no overlapping

585 genotypes/OTUs for the respective libraries. Upon BLAST analysis of dominant OTUs,

586 all were found to be affiliated with members of the Glomeromycota. Thus validating the

587 presence of AM fungi and demonstrating differences across treatments (Table 4). Due to

588 the obligately bi-trophic nature of AM fungi there are limitations in AM sequence

589 availability in reference databases that make taxonomic classification to genus and

590 species level challenging.

591 Table 4 - Taxonomic assignment of representative AM fungal Operational Taxonomic Units (OTUs) 592 derived from clonal AM sequence analysis from Control (C), Glomus (G) and Mixed (M) treatments 593 of Lolium perenne.

\begin{tabular}{llccc}
\hline ID & Affiliation & $\begin{array}{c}\text { Rep. per } \\
\text { OTU }\end{array}$ & $\begin{array}{c}\text { Similarity } \\
{[\%]}\end{array}$ & Treatment \\
C1 & Acaulospora clone & 38 & 99 & Control \\
C48 & Acaulospora clone & 12 & 99 & Control \\
G1 & Uncultured mycorrhizal fungus & 38 & 100 & Glomus \\
G32 & Acaulospora clone & 12 & 99 & Glomus \\
M1 & Acaulospora clone & 25 & 99 & Mixed \\
M7 & Scutellospora clone & 25 & 99 & Mixed \\
\hline
\end{tabular}


596 Clone libraries of the sulfonate mobilising asfA gene amplicons from Control, Glomus

597 and Mixed treatments of L. perenne were screened for diversity via RFLP. Screening of

598150 clones (50 for each treatment) revealed 39 OTUs in total; 17 for the Control (3

599 overlapping), 18 for Glomus (6 overlapping), and 13 for Mixed treatment (8 overlapping).

600 Library coverage was $94 \%, 84 \%$ and $96 \%$ for each respective treatment (Schmalenberger

601 et al., 2007). Of these 39 OTUs, 24 OTUs with more than two representatives were

602 subjected to DNA based sequence identification using BLAST, imported into arb (version

603 5.2), translated into proteins and incorporated into a phylogenetic tree (Figure 10 and 11).

604 There was a 12\% overlap of Control treatment OTUs with Glomus and Mixed treatments

605 and only 3 OTUs occurred in both Control and either AM inoculation treatment (C15A,

606 C18A and C27B) (Table 5). There was a 36\% overlap of Glomus and Mixed treatments

607 with 5 overlapping OTUs that dominate the post-inoculation sulfonate mobilising

608 community (G15A, G34A, G42A, M44A, and M45A) (Table 5). The results suggest that

609 the sulfonate mobilising bacterial community composition (asfA gene) shifts following

610 inoculation.

611 The sequences obtained were subjected to gene comparison using BLAST (Altschul et

612 al., 1990). Sequences of asfA were imported into arb, translated into proteins and

613 integrated into an asfA phylogenetic tree (Schmalenberger et al., 2010) using the

614 randomised axelerated maximum likelihood method. The majority of the Control clones

615 associated closely with the Variovorax and Arthrobacter clade while the Glomus and

616 Mixed treatment clones were most closely associated to Paraburkholderia (for continuity 
617 in tree identified as Burkholderia), Arthrobacter and Rhodococcus clades (Figure 10, 12,

618 respectively). Once again, suggesting that the sulfonate mobilising bacterial community

619 composition is sensitive to inoculation with AM fungi.

620 Table 5 - Taxonomic assignment of representative desulfonating OTUs derived from clonal asfA 621 DNA sequence analysis from AM hyphae of Lolium perenne, either uninoculated (Control), 622 inoculated with $R$. irregularis (Glomus), or inoculated with a mix of 6 arbuscular mycorrhizal fungi 623 (Mixed).

\begin{tabular}{|c|c|c|c|c|c|}
\hline \multirow[t]{3}{*}{ ID } & \multirow[t]{3}{*}{ Affiliation } & \multirow{3}{*}{$\begin{array}{l}\text { Similarity } \\
{[\%]}\end{array}$} & \multirow{2}{*}{\multicolumn{3}{|c|}{$\begin{array}{c}\text { Representatives per } \\
\text { OTU/Treatment }\end{array}$}} \\
\hline & & & & & \\
\hline & & & Control & Glomus & Mixed \\
\hline C13B & Variovorax species & 80 & 3 & & \\
\hline $\mathrm{C} 15 \mathrm{~A}$ & $\begin{array}{l}\text { Mycobacterium } \\
\text { smegmatis }\end{array}$ & 79 & 6 & & 2 \\
\hline $\mathrm{C} 18 \mathrm{~A}$ & $\begin{array}{l}\text { Mycobacterium } \\
\text { smegmatis }\end{array}$ & 78 & 5 & & 2 \\
\hline $\mathrm{C} 21 \mathrm{~A}$ & Variovorax paradoxus & 86 & 4 & & \\
\hline $\mathrm{C} 25 \mathrm{~A}$ & Variovorax paradoxus & 97 & 2 & & \\
\hline $\mathrm{C} 27 \mathrm{~B}$ & Variovorax paradoxus & 82 & 2 & 1 & \\
\hline $\mathrm{C} 30 \mathrm{~A}$ & Variovorax species & 81 & 2 & & \\
\hline C31A & $\begin{array}{l}\text { Mycobacterium } \\
\text { smegmatis }\end{array}$ & 79 & 3 & & \\
\hline $\mathrm{C} 41 \mathrm{~A}$ & Variovorax species & 80 & 3 & & \\
\hline $\mathrm{C} 42 \mathrm{~B}$ & Variovorax species & 82 & 3 & & \\
\hline $\mathrm{C} 43 \mathrm{~A}$ & Variovorax paradoxus & 81 & 4 & & \\
\hline $\mathrm{C} 43 \mathrm{~B}$ & Variovorax paradoxus & 86 & 4 & & \\
\hline $\mathrm{C} 4 \mathrm{~A}$ & Variovorax paradoxus & 86 & 4 & & \\
\hline G15A & Rhodococcus erythropolis & 97 & & 6 & 5 \\
\hline G34A & $\begin{array}{l}\text { uncultured } \\
\text { proteobacterium partial }\end{array}$ & 76 & & 11 & 22 \\
\hline G38A & $\begin{array}{l}\text { Mycobacterium } \\
\text { smegmatis }\end{array}$ & 79 & & 8 & \\
\hline G42A & $\begin{array}{l}\text { Mycobacterium } \\
\text { smegmatis }\end{array}$ & 74 & & 1 & 2 \\
\hline G42B & $\begin{array}{l}\text { uncultured } \\
\text { proteobacterium }\end{array}$ & 79 & & 3 & \\
\hline M15B & $\begin{array}{l}\text { uncultured } \\
\text { proteobacterium }\end{array}$ & 76 & & & 2 \\
\hline M29A & $\begin{array}{l}\text { uncultured } \\
\text { proteobacterium partial }\end{array}$ & 76 & & & 3 \\
\hline M37A & $\begin{array}{l}\text { uncultured } \\
\text { proteobacterium partial }\end{array}$ & 77 & & & 4 \\
\hline M44A & $\begin{array}{l}\text { Uncultured Variovorax } \\
\text { sp. }\end{array}$ & 76 & & 2 & 1 \\
\hline M45A & Variovorax paradoxus & 86 & & 2 & 3 \\
\hline
\end{tabular}


bioRxiv preprint doi: https://doi.org/10.1101/2021.06.22.449381; this version posted June 22, 2021. The copvright holder for this preprint (which was not certified by peer review) is the author/funder, who has granted bioRxiv a license to display the preprint in perpetuity. It is made available under aCC-BY-NC-ND 4.0 International license.

M49A uncultured

624 


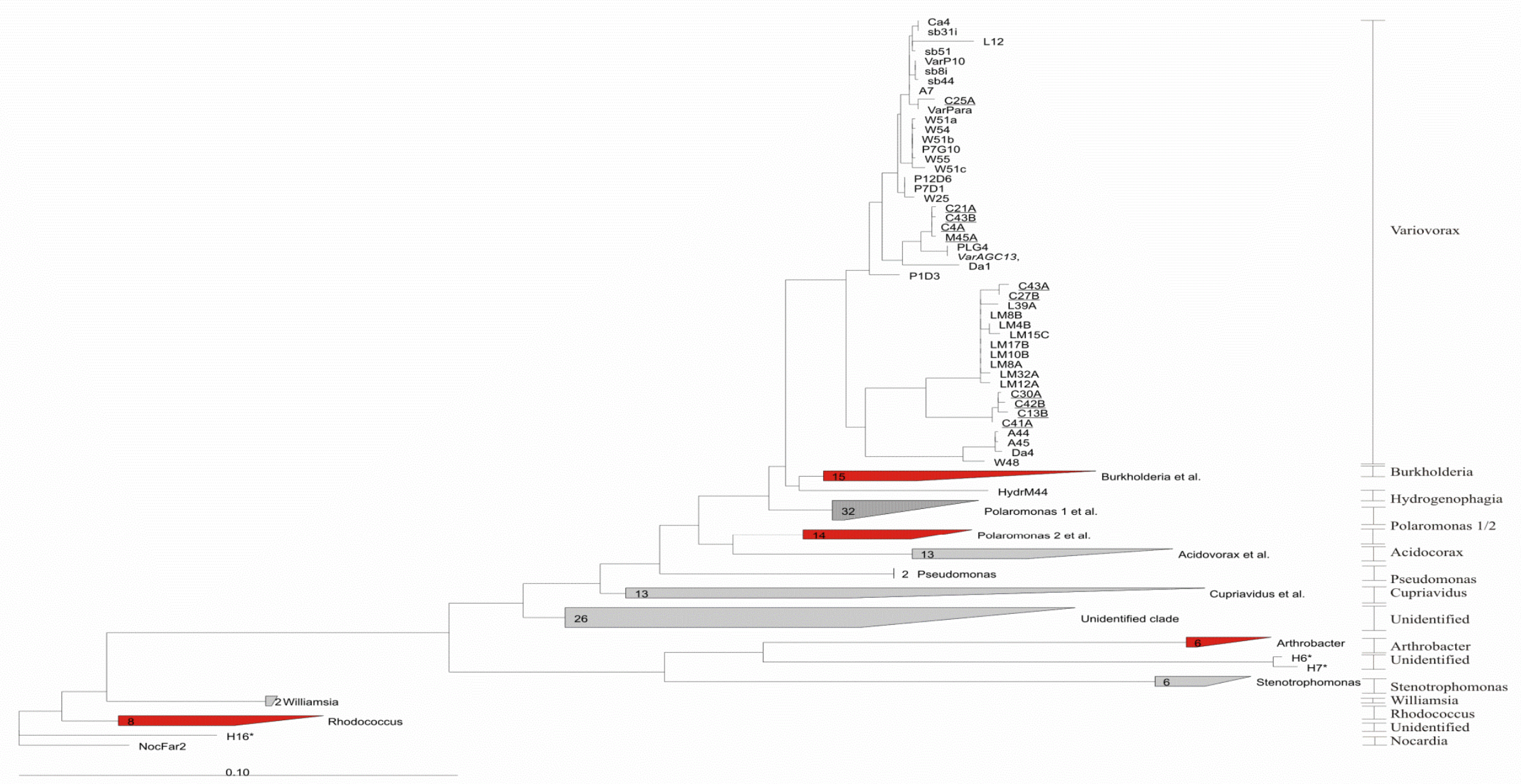

626 Figure 10 - Randomised axelerated maximum likelihood tree of truncated Asf A sequences with the Variovorax clade expanded. C, G and M indicate Control, Glomus 627 and Mixed treatments. Cultivated (italised) and molecular isolates from this study are underlined. Molecular isolates from spring barley rhizospheres (sb; 628 (Schmalenberger \& Kertesz, 2007)), Agrostis grassland rhizospheres (CA; (Schmalenberger et al., 2010)), wheat rhizospheres from Broadbalk (W; (Schmalenberger 629 et al., 2008)), rhizospheres and soils from the Damma glacier forefield (D; DA; (Schmalenberger et al., 2010)) were isolated previously. Highlighted in red are clades 630 to be expanded in Figure 11 below. 


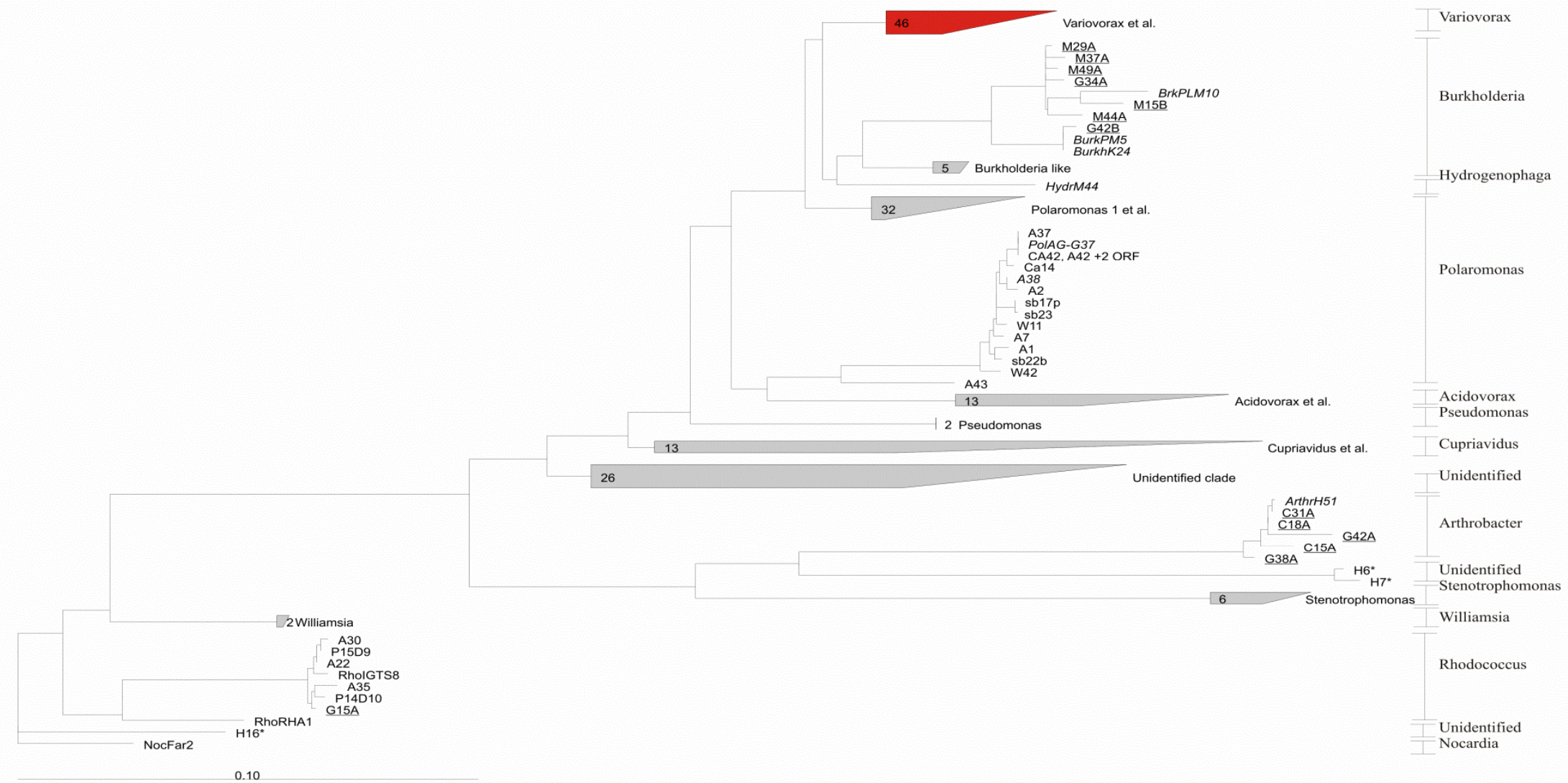

633 Figure 11 - Randomised axelerated maximum likelihood tree of truncated Asf A sequences with the clades minimised in the above figure (red) expanded. $\mathrm{C}$, $\mathrm{G}$ and $\mathrm{M}$ indicate Control, Glomus and Mixed treatments. Cultivated (italised) and molecular isolates from this study are underlined. Molecular isolates from spring barley rhizospheres (sb; (Schmalenberger \& Kertesz, 2007)), Agrostis grassland rhizospheres (CA; (Schmalenberger et al., 2010)), wheat rhizospheres from Broadbalk (W;

636 (Schmalenberger et al., 2008)), rhizospheres and soils from the Damma glacier forefield (D; DA; (Schmalenberger \& Noll, 2010)) were isolated previously. Highlighted 637 in red are clades expanded in Figure 10 above. 


\section{Discussion}

640 Numerous studies have shown that AM inoculation promotes plant growth (Wang et al., 2011, Pellegrino et al., 2012, Faye et al., 2013). Indeed, AM fungi interact synergistically with functional soil microbial populations for $\mathrm{P}$ and $\mathrm{N}$ mobilisation (Hodge et al., 2001, Read \& Perez-Moreno, 2003, Hodge \& Fitter, 2010). However, rarely has the effect of AM fungal inoculation and AM fungal associated microbiota been examined in the context of organo-S

645 mobilisation. This study aimed to investigate the impact of AM fungal inoculation practices on organo-S transforming microbial community dynamics to potentially improve nutrient supply and promote plant growth. The experiments undertaken demonstrated that AM inoculation significantly increases root colonisation, plant growth, and impacts organo-S mobilising microbial communities.

650 For the PGP pot experiments, the mono-species $R$. irregularis (Glomus) and mixed AM fungal treatments increased above and belowground plant biomass over the control experiment. Additionally, increases in biomass yield was less pronounced with the mono-species in comparison to the mixed inoculation, this result suggests that mixed AM inoculants have an increased probability of successfully forming an efficiently functional symbiosis. Indeed, many

655 studies corroborate this finding and show that mixed species inoculants exert more beneficial effects in comparison to their mono-species counterparts as a result of increased symbiotic potential arising from multiple species with differential characteristics (Rowe et al., 2007, Faye et al., 2013, Jin et al., 2013). The autoclaved mixed inoculant increased growth more so than the un-inoculated control, however, the PGP effect was significantly less than that observed 660 with the biotic mixed inoculant. Rowe et al. (2007) demonstrated that increased growth can be a result of the substrate in which the inoculant is supplied. Indeed, in an experiment comparing commercial inoculants with 7 different host plants, 5 exhibited increased growth as a result of 
the inoculant substrate alone thus providing an explanation for the PGP effect obtained with the present AC-Control inoculum (Rowe et al., 2007).

665 AM inoculation significantly increased root colonisation for both the bi-compartmental microcosms and the PGP pot experiments. Tresender (2013) demonstrated a proportionality between increased AM root colonisation and both plant yield and nutrient content (Treseder, 2013), a potential mechanism for which is the increased efficiency of nutrient transfer via characteristic mycorrhizal structures (Van Der Heijden et al., 1988, Klironomos \& Hart, 2002).

670 An experiment carried out to ascertain the impact of commercial AM fungal inoculant on colonisation rates in Pisum sativum demonstrated that mono-species (G. intraradices) and mixed AM inoculant (G. intraradices, G. mosseae, and G. clarum) both significantly increased AM colonisation but there was not an additional benefit of mixed over mono-species inoculation (Jin et al., 2013). Despite the equal colonisation capacity of both AMF treatments

675 in the present study, the multi-species (Mixed) treatment increased biomass to a greater extent than the single species (Glomus) treatment. This may be the result of differential nutrient uptake efficiency for multiple distinct AM fungal species in the mixed treatment that is not associated with colonisation capacities and this leading to increased plant biomass yield (Marschner \& Dell, 1994).

680 Cultivable community quantification revealed that total heterotrophic and sulfonate mobilising bacterial communities are larger in the hyphosphere than bulk soil and these findings are consistent with previous studies (Johansson et al., 2004, Gahan \& Schmalenberger, 2015). For the bi-compartmental microcosms, cultivable heterotrophic and sulfonate mobilising bacterial communities increased in abundance following Mixed treatment for L. perenne, only. For $P$.

685 lanceolata, an increased cultivable heterotrophic community was observed in the $R$. irregularis single species treatment (Glomus). There was not an effect of AM inoculation on the sulfonate 
mobilising community for P. lanceolata or A. stolonifera. However, the sulfonate mobilising communities were an order of magnitude higher for both plants. The chemical composition of root exudates is dependent on plant species and has been shown to alter microbial community 690 composition and abundance (Lynch \& Whipps, 1990, Grayston et al., 1998). The characteristic root exudates of $A$. stolonifera and $P$. lanceolata may, therefore, have selectively stimulated larger indigenous communities of sulfonate mobilisers negating the requirement to expend the Control to AM fungi to further stimulate these populations (Jones et al., 2004b). For the PGP pot experiment, unlike the bi-compartmental microcosms, increased abundances of sulfonate mobilisers were observed following both Glomus and Mixed inoculations. The duration of this experiment was 10 weeks in comparison to 6 months for the bi-compartmental microcosms. Evidence suggests that $\mathrm{S}$ requirement is highest at early stages of vegetative growth (Kertesz et al., 2007, Gahan et al., 2021), therefore, unlike the bi-compartmental microcosms, the Control may have been allocated to AMF associated microbial populations to facilitate 700 mobilisation of sulfonates to fulfil the plants $\mathrm{S}$ requirement.

Bacterial isolates capable of mobilising sulfonates in possession of the asfA gene were found to belong to classes such as Alphaproteobacteria, Betaproteobacteria, and the Actinobacteria. Sequences identified include; Variovorax, Paraburkholderia, Agrobacterium, Polaromonas, Rhodococcus, and Mesorhizobium. Variovorax, Polaromonas and Rhodococcus species have 705 previously been extracted from the rhizosphere of wheat and have a sulfonate mobilising asfA gene (Kertesz et al., 2007, Schmalenberger \& Kertesz, 2007, Schmalenberger et al., 2008, Schmalenberger et al., 2009). Paraburkholderia, Agrobacterium and Mesorhizobium species are newly associated with sulfonate mobilising activity and, furthermore, were only isolated from the AM inoculated treatments due to potential AM specific induced modification of the 710 soil microbial environment (Badri et al., 2013). The genera Paraburkholderia/Burkholderia and Agrobacterium have been linked with AM and bacterial interactions and PGP stemming 
from their ability to mobilise P (Gentili \& Jumpponen, 2006). Additionally, Mesorhizobium species have been shown to be involved in N fixation (Kaneko et al., 2000) and PGP for both chickpea and barley by certain phosphate solubilising strains (Peix et al., 2001). Cultivation

715 independent analysis of the sulfonate mobilising asfA gene corroborates the cultivation dependent work and revealed minimal overlap of genotypes across treatments. The majority of the Control clones associated closely with the Variovorax and Arthrobacter clade while the Glomus and Mixed treatment clones were most closely associated to Paraburkholderia, Arthrobacter and Rhodococcus clades. This result demonstrates that AM inoculation stimulates

720 shifts in the sulfonate mobilising bacterial community. Indeed, AM induced alteration of the sulfonate mobilising bacterial community has been observed previously with DNA extracted from hyphosphere of grassland swards (Gahan \& Schmalenberger, 2015).

Community fingerprinting, undertaken for the bi-compartmental microcosms, identified a bacterial and fungal community shift following AMF inoculation. This was expected, as AM 725 fungal symbiosis has been shown to alter microbial community composition in the hyphosphere (Johansson et al., 2004, Gahan \& Schmalenberger, 2015). Van der Heijden et al., (1998) demonstrated using mono and mixed species inoculations, that growth promotion associated with AMF inoculation was only as good as the most effective AM species in the mix inoculated in isolation. This may provide an explanation for community shifts following 730 the Glomus inoculation but no additional additive shift following Mixed inoculation as observed for A. stolonifera and P. lanceolata. As observed for root colonisation and cultivation-based analysis of desulfonating communities, L. perenne displayed the greatest sensitivity to both AMF inoculation treatments for the cultivation independent community fingerprinting. Helgason et al. (2002) provided an explanation for this by demonstrating that 735 root colonisation, plant-fungal symbiont compatibility and subsequent overall plant vigour were subject to variation depending on the specific AM-plant fungal combination (Helgason et 
al., 2002). It is important, therefore, to select a suitable AMF-plant symbiotic partnership before implementing AMF inoculation practices.

Inoculation with AM fungi can both promote plant growth and stimulate proliferation of

740 bacteria involved in mineralisation of sulfonate-S. Interactions between AM fungi and bacteria have great potential for use in agriculture to improve $\mathrm{S}$ supply to plants when available $\mathrm{SO}_{4}{ }^{2-}$ becomes a limiting factor to growth. The present study also highlights the selective nature of plant receptivity to AM fungi and the importance of careful selection of a high quality AM fungal inoculant suited specifically to the intended ecosystem. 
- Altschul SF, Gish W, Miller W, Myers EW \& Lipman DJ (1990) Basic local alignment search tool. Journal of Molecular Biology 215: 403-410.

- Andrade MMM, Stamford NP, Santos CERS, Freitas ADS, Sousa CA \& Junior MAL (2013) Effects of biofertilizer with diazotrophic bacteria and mycorrhizal fungi in soil attribute, cowpea nodulation yield and nutrient uptake in field conditions. Scientia Horticulturae 162: 374-379.

- Autry AR \& Fitzgerald JW (1990) Sulfonate S: a major form of forest soil organic sulfur. Biology and Fertility of Soils 10: 50-56.

770 - Badri DV, Chaparro JM, Zhang R, Shen Q \& Vivanco JM (2013) Application of Natural Blends of Phytochemicals Derived from the Root Exudates of Arabidopsis to the Soil Reveal That Phenolic-related Compounds Predominantly Modulate the Soil Microbiome. Journal of Biological Chemistry 288: 4502-4512.

- Barea JM, Azcón R \& Azcón-Aguilar C (2002) Mycorrhizosphere interactions to improve plant fitness and soil quality. Antonie van Leeuwenhoek 81: 343-351.

- Barrios E (2007) Soil biota, ecosystem services and land productivity. Ecological Economics 64: 269-285.

- Berruti A, Borriello R, Orgiazzi A, Barbera AC, Lumini E \& Bianciotto V (2014) Arbuscular Mycorrhizal Fungi and their Value for Ecosystem Management. Biodiversity:

780 The Dynamic Balance of the Planet,(Grillo O, ed.). Intech Open.

- Bougoure DS \& Cairney JWG (2005) Fungi associated with hair roots of Rhododendron lochiae (Ericaceae) in an Australian tropical cloud forest revealed by culturing and culture independent molecular methods. Environmental Microbiology 7: 1743-1754.

- Bünemann EK, Schwenke GD \& Van Zwieten L (2006) Impact of agricultural inputs on soil organisms-a review. Soil Research 44: 379-406.

- Dodd IC \& Ruiz-Lozano JM (2012) Microbial enhancement of crop resource use efficiency. Current Opinion in Biotechnology 23: 236-242.

- Eichhorn E, van der Ploeg JR \& Leisinger T (1999) Characterization of a two-component alkanesulfonate monooxygenase from Escherichia coli. Journal of Biological Chemistry

790 274: 26639-26646.

- Faye A, Dalpé Y, Ndung'u-Magiroi K, Jefwa J, Ndoye I, Diouf M \& Lesueur D (2013) Evaluation of commercial arbuscular mycorrhizal inoculants. Canadian Journal of Plant Science 93: 1201-1208.

- FDA (2011) BAM Appendix 2: Most Probable Number from Serial Dilutions. (Blodgett 795 R, ed.).

- Fox A, Kwapinski W, Griffiths BS \& Schmalenberger A (2014) The role of sulfur and phosphorus mobilizing bacteria in biochar induced growth promotion of Lolium perenne. FEMS Microbiology Ecology 90: 78-91.

- Gahan J \& Schmalenberger A (2015) Arbuscular mycorrhizal hyphae in grassland select

800 for a diverse and abundant hyphospheric bacterial community involved in sulfonate desulfurization. Applied Soil Ecology 89: 113-121.

- Gahan J, O'Sullivan O, Cotter P \& Schmalenberger A (2021) The role of arbuscular mycorrhiza and organosulfur mobilizing bacteria in plant sulphur supply. bioRxiv 2021.2002.2008.429889.

805 - Gardes M \& Bruns TD (1993) ITS primers with enhanced specificity for Basidiomycetes: application to the identification of mycorrhizae and rusts. Molecular Ecology 2: 113-118. 
- Gentili F \& Jumpponen A (2006) Potential and possible uses of bacterial and fungal biofertilizers. Haworth Press, New York.

- Gianinazzi S \& Vosátka M (2004) Inoculum of arbuscular mycorrhizal fungi for production systems: science meets business. Canadian Journal of Botany 82: 1264-1271.

- Grayston SJ, Wang S, Campbell CD \& Edwards AC (1998) Selective influence of plant species on microbial diversity in the rhizosphere. Soil Biology and Biochemistry 30: 369378.

$815 \quad$ wood-wide web? Nature 394: 431-431.

- Helgason T, Merryweather JW, Denison J, Wilson P, Young JPW \& Fitter AH (2002) Selectivity and functional diversity in arbuscular mycorrhizas of co-occurring fungi and plants from a temperate deciduous woodland. Journal of Ecology 90: 371-384.

- Hodge A \& Fitter AH (2010) Substantial nitrogen acquisition by arbuscular mycorrhizal 820 fungi from organic material has implications for $\mathrm{N}$ cycling. Proceedings of the National Academy of Sciences 107: 13754-13759.

- Hodge A, Campbell CD \& Fitter AH (2001) An arbuscular mycorrhizal fungus accelerates decomposition and acquires nitrogen directly from organic material. Nature 413: 297-299.

825 Mutualistic mycorrhiza-like symbiosis in the most ancient group of land plants. Nature Communications 1: 103.

- Jin H, Germida JJ \& Walley FL (2013) Impact of arbuscular mycorrhizal fungal inoculants on subsequent arbuscular mycorrhizal fungi colonization in pot-cultured field pea (Pisum sativum L.). Mycorrhiza 23: 45-59.

830 - Johansson JF, Paul LR \& Finlay RD (2004) Microbial interactions in the mycorrhizosphere and their significance for sustainable agriculture. FEMS Microbiolial Ecology 48: 1-13.

- Jones DL, Hodge A \& Kuzyakov Y (2004b) Plant and mycorrhizal regulation of rhizodeposition. New Phytologist 163: 459-480.

835 - Kaneko T, Nakamura Y, Sato S, Asamizu E, Kato T, Sasamoto S, Watanabe A, Idesawa K, Ishikawa A \& Kawashima K (2000) Complete genome structure of the nitrogen-fixing symbiotic bacterium Mesorhizobium loti. DNA Research 7: 331-338.

- Kertesz MA \& Mirleau P (2004) The role of microbes in plant sulphur supply. Journal of Experimental Botany 55: 1939-1945.

840 - Kertesz MA, Fellows E \& Schmalenberger A (2007) Rhizobacteria and plant sulfur supply. Advances in Applied Microbiology 62: 235-268.

- King JE \& Quinn JP (1997) The utilization of organosulphonates by soil and freshwater bacteria. Letters in Applied Microbiology 24: 474-478.

845 using different sources of inoculum. Mycorrhiza 12: 181-184.

- Lane DJ (1991) Nucleic Acid Techniques in Bacterial Systematics. John Wiley \& Sons, Chichester, UK.

- Ludwig W, Strunk O, Westram R, et al. (2004) ARB: a software environment for sequence data. Nucleic Acids Research 32: 1363-1371.

850 - Lynch JM \& Whipps JM (1990) Substrate flow in the rhizosphere. Plant Soil 129: 1-10.

- Marschner H \& Dell B (1994) Nutrient uptake in mycorrhizal symbiosis. Plant and Soil 159: 89-102.

- McGonigle TP, Miller MH, Evans DG, Fairchild GL \& Swan JA (1990) A new method which gives an objective measure of colonization of roots by vesicular-arbuscular mycorrhizal fungi. New Phytologist 115: 495-501. 
- McGrath SP, Zhao FJ \& Blake-Kalff MM (2003) History and outlook for sulphur fertilizers in Europe. Vol. Proceedings 497. York, UK.

- Muyzer G, De Waal E \& Uitterlindin AG (1993) Profiling of complex microbial populations by denaturing gradient gel electrophoresis analysis of polymerase chain reaction-amplified genes coding for 16S rRNA. Applied and Environmental Microbiology 59: 695-700.

- Öpik M, Moora M, Liira J \& Zobel M (2006) Composition of root-colonizing arbuscular mycorrhizal fungal communities in different ecosystems around the globe. Journal of Ecology 94: 778-790.

865 - Peix A, Rivas-Boyero AA, Mateos PF, Rodriguez-Barrueco C, Martınez-Molina E \& Velazquez E (2001) Growth promotion of chickpea and barley by a phosphate solubilizing strain of Mesorhizobium mediterraneum under growth chamber conditions. Soil Biology and Biochemistry 33: 103-110.

- Pellegrino E, Turrini A, Gamper HA, Cafa G, Bonari E, Young JPW \& Giovannetti M 870 (2012) Establishment, persistence and effectiveness of arbuscular mycorrhizal fungal inoculants in the field revealed using molecular genetic tracing and measurement of yield components. New Phytologist 194: 810-822.

- Plenchette C, Clermont-Dauphin C, Meynard JM \& Fortin JA (2005) Managing arbuscular mycorrhizal fungi in cropping systems. Canadian Journal of Plant Science 85: 31-40.

875 - Ray DK, Mueller ND, West PC \& Foley JA (2013) Yield trends are insufficient to double global crop production by 2050. PloS One 8: e66428.

- Read DJ \& Perez-Moreno J (2003) Mycorrhizas and nutrient cycling in ecosystems-a journey towards relevance? New Phytologist 157: 475-492.

- Reasoner DJ \& Geldreich EE (1985) A new medium for the enumeration and subculture

880 of bacteria from potable water. Applied and Environmental Microbiology 49: 1-7.

- Rowe HI, Brown CS \& Claassen VP (2007) Comparisons of mycorrhizal responsiveness with field soil and commercial inoculum for six native montane species and Bromus tectorum. Restoration Ecology 15: 44-52.

- Schmalenberger A \& Kertesz MA (2007) Desulfurization of aromatic sulfonates by rhizosphere bacteria: high diversity of the asfA gene. Environmental Microbiology 9: 535545 .

- Schmalenberger A \& Noll M (2010) Shifts in desulfonating bacterial communities along a soil chronosequence in the forefield of a receding glacier. FEMS Microbiol Ecol 71: 208217.

890 - Schmalenberger A, Schwieger F \& Tebbe CC (2001) Effect of primers hybridizing to different evolutionarily conserved regions of the small-subunit rRNA gene in PCR-based microbial community analyses and genetic profiling. Applied and Environmental Microbiology 67: 3557-3563.

- Schmalenberger A, Drake HL \& Kuesel K (2007) High unique diversity of sulfatereducing prokaryotes characterized in a depth gradient in an acidic fen. Environmental Microbiology 9: 1317-1328.

- Schmalenberger A, Telford A \& Kertesz MA (2010) Sulfate treatment affects desulfonating bacterial community structures in Agrostis rhizospheres as revealed by functional gene analysis based on asfA. European Journal of Soil Biology 46: 248-254.

- Schmalenberger A, Hodge S, Hawkesford MJ \& Kertesz MA (2009) Sulfonate desulfurization in Rhodococcus from wheat rhizosphere communities. FEMS Microbiolial Ecoloy 67: 140-150.

- Schmalenberger A, Hodge S, Bryant A, Hawkesford MJ, Singh BK \& Kertesz MA (2008) The role of Variovorax and other Comamonadaceae in sulfur transformations by microbial 
905 wheat rhizosphere communities exposed to different sulfur fertilization regimes. Environmental Microbiology 10: 1486-1500.

- Schmalenberger A, Hodge S, Bryant A, Hawkesford MJ, Singh BK \& Kertesz MA (2008) The role of Variovorax and other Comamonadaceae in sulfur transformations by microbial wheat rhizosphere communities exposed to different sulfur fertilization regimes.

$910 \quad$ Environmental Microbiology 10: 1486-1500.

- Simon L, Lalonde M \& Bruns TD (1992) Specific amplification of 18S fungal ribosomal genes from vesicular-arbuscular endomycorrhizal fungi colonizing roots. Applied and Environmental Microbiology 58: 291-295.

- Smit AL, Bindraban PS, Schröder JJ, Conijn JG \& Van der Meer HG (2009) Phosphorus

915 in agriculture: global resources, trends and developments. Report to the Steering Committee Technology Assessment of the Ministry of Agriculture, The Neetherlands, Wageningen.

- Treseder KK (2013) The extent of mycorrhizal colonization of roots and its influence on plant growth and phosphorus content. Plant and Soil 371: 1-13.

920 - Tunney H, Kirwan L, Fu W, Culleton N \& Black AD (2010) Long-term phosphorus grassland experiment for beef production-impacts on soil phosphorus levels and liveweight gains. Soil Use and Management 26: 237-244.

- Van Der Heijden MGA, Klironomos JN, Ursic M, Moutoglis P, Streitwolf-Engel R, Boller T, Wiemken A \& Sanders IR (1988) Mycorrhizal fungal diversity determines plant

925 biodiversity, ecosystem variability and productivity. Geological Society of America Bulletin 100: 912-927.

- Vermeij P, Wietek C, Kahnert A, Wüest T \& Kertesz MA (1999) Genetic organization of sulphur-controlled aryldesulphonation in Pseudomonas putida S-313. Molecular Microbiology 32: 913-926.

930 - Vilarino A, Frey B \& Shüepp H (1997) MES [2-(N-morpholine)-ethane sulphonic acid] buffer promotes the growth of external hyphae of the arbuscular mycorrhizal fungus Glomus intraradices in an alkaline sand. Biology and Fertility of Soils 25: 79-81.

- Wang FY, Tong RJ, Shi ZY, Xu XF \& He XH (2011) Inoculations with arbuscular mycorrhizal fungi increase vegetable yields and decrease phoxim concentrations in carrot

935 and green onion and their soils. PloS One 6: e16949.

- White TJ, Bruns T, Lee S \& Taylor J (1990) Amplification and direct sequencing of fungal ribosomal RNA genes for phylogenetics. PCR Protocols: A Guide to Methods and Applications 315-322.

- Zhao FJ, Lehmann J, Solomon D, Fox MA \& McGrath SP (2006) Sulphur speciation and $940 \quad$ turnover in soils: evidence from sulphur K-edge XANES spectroscopy and isotope dilution studies. Soil Biology and Biochemistry 38: 1000-1007.

\section{Acknowledgements}

The authors would like to thank the staff of Teagasc, Johnstown Castle, for providing the soil 